\title{
Lead coprecipitation with iron oxyhydroxide nano-particles
}

\author{
Peng Lu ${ }^{\mathrm{a}, 1}$, Noel T. Nuhfer ${ }^{\mathrm{b}}$, Shelly Kelly ${ }^{\mathrm{c}, 2}$, Qin $\mathrm{Li}^{\mathrm{a}}{ }^{\mathrm{a}, \mathrm{d}, 1,3}$, Hiromi Konishi ${ }^{\mathrm{a}, \mathrm{e}, 1,3}$, \\ Erika Elswick $^{\text {a, }}$, Chen Zhu ${ }^{\text {a, } *, 1}$ \\ ${ }^{a}$ Department of Geological Sciences, Indiana University, Bloomington, IN 47405-1405, United States \\ ${ }^{\mathrm{b}}$ Carnegie Mellon University, Department of Materials Sciences and Engineering, Pittsburgh, PA 15260, United States \\ ${ }^{\mathrm{c}}$ Argonne National Laboratory, Biosciences Division, Argonne, IL 60439-4843, United States \\ ${ }^{\mathrm{d}}$ State Key Laboratory of Pollution Control and Resource Reuse, School of the Environment, Nanjing University, Nanjing 210093, China \\ ${ }^{\mathrm{e}}$ Department of Geoscience, University of Wisconsin-Madison, Madison, WI 53706, United States
}

Received 19 April 2010; accepted in revised form 17 May 2011; available online 2 June 2011

\begin{abstract}
$\mathrm{Pb}^{2+}$ and $\mathrm{Fe}^{3+}$ coprecipitation was studied with sorption edge measurements, desorption experiments, sorbent aging, High Resolution Transmission and Analytical Electron Microscopy (HR TEM-AEM), and geochemical modeling. Companion adsorption experiments were also conducted for comparison. The macroscopic chemical and near atomic scale HRTEM data supplemented our molecule scale analysis with EXAFS (Kelly et al., 2008). Coprecipitation of $\mathrm{Pb}^{2+}$ with ferric oxyhydroxides occurred at $\sim \mathrm{pH} 4$ and is more efficient than adsorption in removing $\mathrm{Pb}^{2+}$ from aqueous solutions at similar sorbate/sorbent ratios and $\mathrm{pH}$. X-ray Diffraction (XRD) shows peaks of lepidocrocite and two additional broad peaks similar to fine particles of 2-line ferrihydrite (2LFh). HRTEM of the Pb-Fe coprecipitates shows a mixture of 2-6 nm diameter spheres and 8-20 by 200-300 nm needles, both uniformly distributed with $\mathrm{Pb}^{2+}$. Geochemical modeling shows that surface complexation models fit the experimental data of low $\mathrm{Pb}: \mathrm{Fe}$ ratios when a high site density is used. Desorption experiments show that more $\mathrm{Pb}^{2+}$ was released from loaded sorbents collected from adsorption experiments than from $\mathrm{Pb}$ to Fe coprecipitates at dilute EDTA concentrations. Desorbed $\mathrm{Pb}^{2+}$ versus dissolved $\mathrm{Fe}^{3+}$ data show a linear relationship for coprecipitation $(\mathrm{CPT})$ desorption experiments but a parabolic relationship for adsorption (ADS) experiments.

Based on these results, we hypothesize that $\mathrm{Pb}^{2+}$ was first adsorbed onto the nanometer-sized, metastable, iron oxyhydroxide polymers of $2 \mathrm{LFh}$ with domain size of $2-3 \mathrm{~nm}$. As these nano-particles assembled into larger particles, some $\mathrm{Pb}^{2+} \mathrm{was}^{-}$ trapped in the iron oxyhydroxide structure and re-arranged to form solid solutions. Therefore, the CPT contact method produced more efficient removal of $\mathrm{Pb}^{2+}$ than the adsorption contact method, and $\mathrm{Pb}^{2+}$ bound in $\mathrm{CPT}$ solids represent a more stable sequestration of $\mathrm{Pb}^{2+}$ in the environment than $\mathrm{Pb}^{2+}$ adsorbed on iron oxyhydroxide surfaces.
\end{abstract}

(c) 2011 Elsevier Ltd. All rights reserved.

\section{INTRODUCTION}

The bioavailability, mobility, transport, distribution, and cycling of trace metals in subsurface and surficial

\footnotetext{
* Corresponding author. Address: 1001 E 10th St., Bloomington, IN 47405, United States. Tel.: +1 812856 1884; fax: +1 812855 7899.

E-mail address: chenzhu@indiana.edu (C. Zhu).

${ }^{1}$ Present address: Calera Corporation, Los Gatos, CA 95032, United States.

${ }^{2}$ Present address: UOP, A Honeywell Company, United States.

${ }^{3}$ Present address.
}

geological systems are often regulated by iron cycling (Krauskopf, 1956; Jenne, 1968; Davis and Kent, 1990). Iron oxyhydroxides occur widely in surficial and subsurface geological environments, and even though they may constitute a minor fraction of the bulk rock, soil, or sediment, they are efficient scavengers of trace metals and radionuclides (Jambor and Dutrizac, 1998). However, the mechanisms by which trace elements are sorbed onto iron oxyhydroxides in pristine and anthropogenically impacted geological systems are not well known. Knowledge of sorption mechanisms is nevertheless central to both developing quantitative partitioning models that serve as a theoretical basis for the 
application of trace elements as signatures of fluid flow and chemical reactions, and to predicting contaminant transport and stability in geological media.

Presence of lead $\left(\mathrm{Pb}^{2+}\right)$ in the environment has severe adverse effects on human health, particularly for infants and young children (Nriagu, 1992). Also, the study of lead isotopes is of great interest to geologists. Possible mechanisms in controlling lead concentrations in aqueous solutions include solubility, surface adsorption, surface precipitation, and coprecipitation (CPT). Coprecipitation is often referred to as the simultaneous removal of a trace constituent, together with a carrier constituent, from a homogeneous aqueous solution. However, the mechanism of coprecipitation is poorly understood. The term coprecipitation is loosely used in a phenomenological sense, alluding to the centuryold observation that trace constituents, often metals, are efficiently removed together with a major constituent from a homogeneous aqueous solution.

In the following discussion, "coprecipitation experiments" refers to the design in which the tracer (e.g., $\mathrm{Pb}^{2+}$ ) is present in the solution when the carrier ion (e.g., $\mathrm{Fe}^{3+}$ ) hydrolyzes and precipitates to form hydrous oxides. In "adsorption experiments" (ADS), the tracer is added to a suspension of already precipitated and aged (typically for a period of a few hours to a few days) hydrous oxides of the carrier ion (e.g., ferrihydrite). The term "sorption" refers to all processes that transfer an ion from the aqueous phase to the solid phase (Sposito, 1984), without reference to specific processes (e.g., CPT or ADS).

Many geological, environmental, and industrial systems resemble base titration as in our CPT experiments described below. For example, when acid mine drainage loaded with ferric iron and metals is mixed with neutral surface and ground water or reacted with calcite in soils, sediments, and aquifers, $\mathrm{Fe}^{3+}$ and trace metals are simultaneously coprecipitated. Iron oxidation/precipitation may prevail in natural aquatic environments, and thus trace metals are also likely coprecipitated.

Although numerous $\mathrm{Pb}^{2+}$ adsorption experiments have already been conducted (e.g., Gadde and Laitinen, 1973; Kinniburgh et al., 1976; Swallow et al., 1980; Balistrieri and Murray, 1982; Hayes and Leckie, 1986; Rose and Bianchimosquera, 1993; Lutzenkirchen, 1997; Trivedi et al., 2003), studies of coprecipitation are scarce and sporadic (e.g, Ford et al., 1997, 1999; Martinez and Mcbride, 1998, 2001). Pokrovsky et al. (2006a,b) studied coprecipitation of heavy metals including $\mathrm{Pb}$ with natural $\mathrm{Fe}$ oxy(hydr)oxides colloids and Ge coprecipitation with solid Fe oxy(hydr)oxides and its aging. Direct comparison of $\mathrm{Pb}$ ADS and CPT contact methods are even scarcer (Schultz et al., 1987). However, it is important to compare the CPT and ADS methods for the following reasons.

First, sorption behaviors for some metals are different when they are prepared using the CPT or ADS "contact method". Previous work shows that sorption isotherms and sorption $\mathrm{pH}$ edges prepared with ADS and CPT experimental procedures are appreciably different for $\mathrm{Cu}^{2+}$ sorption onto hydrous iron and aluminum oxides (Karthikeyan et al., 1997, 1999). $\mathrm{As}^{5+}$ sorption onto ferrihydrite, and $\mathrm{Ni}^{2+}$ and $\mathrm{Cr}^{3+}$ sorption onto hydrous iron oxides
(Crawford et al., 1993) show similar patterns for ADS and CPT, with coprecipitation being the more efficient process for metal removal from aqueous solutions. CPT sorption edges are located up to $2.6 \mathrm{pH}$ units lower on the uptake-pH diagrams. At the same sorbate/sorbent ratio, metal uptake is enhanced in CPT systems as compared to the ADS system (Charlet and Manceau, 1992; Waychunas et al., 1993; Karthikeyan et al., 1997). However, to illustrate the complexity of the metastable system and metal specific nature, CPT and ADS sorption edges with $\mathrm{Zn}^{2+}$ on iron oxyhydroxide (Crawford et al., 1993) and $\mathrm{Cu}^{2+}$ on hydrous aluminum hydroxide (Karthikeyan et al., 1997) show no appreciable differences, and contradictory experimental results for CPT-ADS have been found for $\mathrm{Cu}^{2+}$ sorption onto iron oxyhydroxide (Swallow et al., 1980; Karthikeyan et al., 1997).

Second, whether or not CPT represents a more permanent sequestration of toxic metals from the environment into iron oxyhydroxide than ADS is an important question. The first iron oxyhydroxide to be precipitated from aqueous solution is commonly ferrihydrite, a poorly ordered and metastable phase, which will subsequently transform to highly ordered phases (e.g., goethite and hematite) over time (Cornell and Schwertmann, 1996). The transformation of metal-ferrihydrite coprecipitates to more ordered phases may lead to structural incorporation of sorbed metals (see summary in Cornell and Schwertmann, 1996), resulting in apparent irreversible sorption or desorption hysteresis.

This paper follows our earlier report on the EXAFS study of the structure of the coprecipitated $\mathrm{Pb}$ onto nanoparticles of iron oxyhydroxides (Kelly et al., 2008), and presents companion laboratory experiments of sorption and desorption of $\mathrm{Pb}^{2+}$ onto iron nano-particles with CPT and ADS contact methods, High-Resolution Transmission and Analytical Electron Microscopy (HR TEM-AEM), and a geochemical modeling study of coprecipitation of $\mathrm{Pb}^{2+}$ with ferric iron. EDTA extraction experiments permit comparison of the strength of $\mathrm{Pb}$ association with nanoparticles of iron oxyhydroxides from the ADS and CPT experiments. To investigate the relative stability of sorbed $\mathrm{Pb}$ in the environment, sorbents from both ADS and CPT experiments were aged at $60{ }^{\circ} \mathrm{C}$ for 14 days and at $90{ }^{\circ} \mathrm{C}$ for $24 \mathrm{~h}$. Desorption experiments were conducted again on aged solids at $60{ }^{\circ} \mathrm{C}$. Finally, we attempt to integrate sorption edge measurements with advanced electron microscopy. The macroscopic chemistry data covering a wide range of conditions was used to supplement the molecular scale EXAFS and HRTEM data, elucidating the $\mathrm{Pb}$ Fe coprecipitation mechanism, and developing a quantitative model for the partitioning of $\mathrm{Pb}^{2+}$ between aqueous solution and iron oxyhydroxides.

\section{MATERIALS AND METHODS}

\subsection{Reagents}

All reagents came from Fisher Scientific, and were of analytical grade. $\mathrm{Fe}-\mathrm{Pb}$ solutions was made from ferric nitrate $\left(\mathrm{Fe}\left(\mathrm{NO}_{3}\right)_{3} \cdot 9 \mathrm{H}_{2} \mathrm{O}\right.$, purity $\left.99.1 \%\right)$ and lead nitrate. All solutions were prepared in a $10 \mathrm{mM} \mathrm{KNO}_{3}$ background electro- 
lyte solution. Laboratory plastic-ware was washed first with a nitric acid solution and then with deionized water.

\subsection{Synthesis of 2-line ferrihydrite}

Two-line ferrihydrite was prepared using the modified procedure of Schwertmann and Cornell (1996). One gram $\mathrm{Fe}\left(\mathrm{NO}_{3}\right)_{3} \cdot 9 \mathrm{H}_{2} \mathrm{O}$ was dissolved in $12.5 \mathrm{~mL}$ deionized water. Bubbling of $\mathrm{N}_{2}$ was used to prevent the possible influence of atmospheric $\mathrm{CO}_{2}$ and to agitate the solution. The $\mathrm{pH}$ of the solution was measured using an Accumet AB15 plus $\mathrm{pH}$ meter, calibrated with buffers ( $\mathrm{pH} \mathrm{4,7,} \mathrm{and} \mathrm{10).} 1 \mathrm{M}$ $\mathrm{KOH}$ was added cumulatively into the vessel until $\mathrm{pH}$ was 7-8. The gel produced was centrifuged and washed with deionized water five times. The gel was then re-suspended in a media of $250 \mathrm{~mL}$ deionized water by ultra-sonification for $10 \mathrm{~min}$ and magnetic stirring for $20 \mathrm{~min}$. The suspended ferrihydrite was aged for $48 \mathrm{~h}$ in closed vessels on an orbital shaker. The freshly prepared gel was used within 2 days for ADS studies. The formation of synthetic 2-line ferrihydrite was confirmed with X-ray diffraction (XRD) analysis as shown in the XRD results section.

\subsection{ADS experiments}

An aliquot of $500 \mathrm{~mL}$ suspended ferrihydrite was used to prepare two batches of solution with different concentrations of $\mathrm{Pb}$, i.e., Batch A (5.25 mM Fe, $0.37 \mathrm{mM} \mathrm{Pb}$, and $10 \mathrm{mM}$ $\left.\mathrm{KNO}_{3}\right)$ and Batch $\mathrm{B}(5.43 \mathrm{mM} \mathrm{Fe}, 0.70 \mathrm{mM} \mathrm{Pb}$, and $10 \mathrm{mM} \mathrm{KNO}_{3}$ ). Fe and $\mathrm{Pb}$ concentrations of the initial solutions were confirmed with a Perkins Elmer 5000 flame and graphite furnace Atomic Adsorption Spectrometer (AAS).

A $50-\mathrm{mL}$ aliquot of the solution (ferrihydrite suspension with the presence of $\mathrm{Pb}$ ) was transferred into a $150-\mathrm{mL}$ high-density polypropylene jar. While stirring the solution vigorously (using Teflon coated magnetic stir bar), $1 \mathrm{M}$ $\mathrm{KOH}$ was injected into the vessel with the rate of $\sim 0.1 \mathrm{~mL} / \mathrm{min}$ while $\mathrm{pH}$ values were continuously monitored. The relatively slow titration rate and vigorous stirring are used to avoid artifacts due to localized high alkalinity during titration as suggested by Martinez and McBride (1998). When the $\mathrm{pH}$ approached the target value (ranged from 4 to 6), a few drops of $0.1 \mathrm{M} \mathrm{KOH}$ were used to reach the desired $\mathrm{pH}$ value. The samples were placed on an orbital shaker for $24 \mathrm{~h}$ after which time the $\mathrm{pH}$ was remeasured. Measurements at every subsequent hour, up to $100 \mathrm{~h}$, showed that solution $\mathrm{pH}$ had stabilized after $24 \mathrm{~h}$.

\subsection{CPT experiments}

Three batches of solution with different concentrations of $\mathrm{Pb}$ were prepared. They are Batch $\mathrm{C}\left(6.27 \mathrm{mM} \mathrm{Fe}^{3+}\right.$, $0.10 \mathrm{mM} \mathrm{Pb}^{2+}$, and $10 \mathrm{mM} \mathrm{KNO}_{3}$ ), Batch $\mathrm{D}(5.77 \mathrm{mM}$ $\mathrm{Fe}^{3+}, 0.37 \mathrm{mM} \mathrm{Pb}^{2+}$, and $10 \mathrm{mM} \mathrm{KNO}_{3}$ ) and Batch $\mathrm{E}$ $\left(6.77 \mathrm{mM} \mathrm{Fe}{ }^{3+}, 0.73 \mathrm{mM} \mathrm{Pb}^{2+}\right.$, and $10 \mathrm{mM} \mathrm{KNO}_{3}$ ). The $\mathrm{Fe}$ and $\mathrm{Pb}$ concentrations of initial solutions were confirmed with AAS analysis.

A 50-mL aliquot of the solution was transferred into a 150 -mL high-density polypropylene jar. While stirring the solution vigorously (using a Teflon coated magnetic stir bar), $1 \mathrm{M} \mathrm{NaOH}$ solution was injected into the vessel with the rate of $\sim 0.1 \mathrm{~mL} / \mathrm{min}$ while constantly recording the $\mathrm{pH}$. When the $\mathrm{pH}$ approached the target value, a few drops of $0.1 \mathrm{M} \mathrm{NaOH}$ were added to reach the desired $\mathrm{pH}$. The samples were put on an orbital shaker for $24 \mathrm{~h}$ after which time the $\mathrm{pH}$ was re-measured.

\subsection{Solid-liquid separation}

The solids were separated by centrifugation at a maximum relative centrifugal force of 4000 ( $\mathrm{RCF}, g$-force) for $45 \mathrm{~min}$ and the liquid supernatant decanted. Precipitates were immediately transferred into capped vials in ethyl alcohol to prevent further reaction before XRD and TEM measurements, which were performed within 1-3 weeks. All supernatants were filtered through a 0.22 micron cellulose membrane filter connected to a $20 \mathrm{~mL}$ polypropylene syringe. The receiving vessel was an air-tight polyethylene centrifugation tube connected to a vacuum pump.

\subsection{Extraction (desorption) experiments}

Room temperature $\left(\sim 22^{\circ} \mathrm{C}\right)$ and high temperature $\left(60^{\circ} \mathrm{C}\right)$ extraction experiments were conducted using ethylenediaminetetra acetic acid (EDTA) to compare the strength of $\mathrm{Pb}$ association with nano-particles of iron oxyhydroxides in both the ADS and CPT experiments (loaded sorbents were all from $\mathrm{pH} 6$ experiments and aged for $24 \mathrm{~h}$ ). To calculate $\mathrm{Pb}$ loading, the $\mathrm{Pb}$ remaining in the supernatant after conclusion of the CPT and ADS experiments was measured and subtracted. The difference between initial $\mathrm{Pb}$ and $\mathrm{Pb}$ found in supernatant was regarded as the total $\mathrm{Pb}$ in subsequent extraction experiments.

For desorption experiments of aged sorbents, the containers with solids for high temperature extraction experiments were immersed in a water bath $\left(60^{\circ} \mathrm{C}\right)$ and aged for 14 days or $90^{\circ} \mathrm{C}$ for $24 \mathrm{~h}$. An aliquot of $80 \mathrm{~mL}$ EDTA solution (with different EDTA concentration) was added to the bottles. The suspension was agitated with an orbital shaker for the designated time. After the extraction or desorption experiments, solid and liquid were separated again according to procedures described in Section 2.5.

\subsection{Analytical methods}

The liquid supernatant was measured for its $\mathrm{pH}$, and was acidified using concentrated ultrapure $\mathrm{HCl}$. These solutions were analyzed for $\mathrm{Fe}$ and $\mathrm{Pb}$ using a Perkins Elmer 5000 flame and graphite furnace AAS (following EPA method 200.7) or a Thermo Jarrell Ash ICAP 61E ICPMS (following EPA method 200.8). All supernatants were stored at $4{ }^{\circ} \mathrm{C}$ until analysis.

The solid specimens were prepared for examination by High-Resolution Transmission Electron Microscopy (HRTEM) first by ultra-sonication in ethyl alcohol to resuspend the particles. Then the suspension was pipetted onto a holey-carbon film supported by a copper-mesh TEM grid, and air-dried. To prevent transformation during ultra-sonication, the vessel with the suspension of coprecipitates and ethyl alcohol was cooled in water. 
The specimens coprecipitated at $\mathrm{pH} 5.2$ and 6.0 were observed with a Philips FEI Tecnai F20 TEM/STEM with a point-to-point resolution of $0.24 \mathrm{~nm}$, and equipped with a Gatan Imaging Filter (GIF) and Energy Dispersive X-ray (EDX) detector, and a JEOL 4000EX with a point-to-point resolution of $0.17 \mathrm{~nm}$, with a Gatan Imaging Filter. The Philips FEI Tecnai F20 TEM/STEM was used for energyfiltered imaging and microanalysis. The JEOL 4000EX HRTEM was used to obtain the highest possible lattice imaging resolution.

$\mathrm{XRD}$ analysis of the $\mathrm{Pb}-\mathrm{Fe}$ coprecipitates was carried out using a Bruker D8 Advance X-ray powder diffractometer ( $\mathrm{Cu} \mathrm{K} \alpha$ radiation), equipped with a solid-state energy-discriminating detector. The scan parameters used were $10.010-80^{\circ} 2 \theta$, with a step size of $0.02^{\circ} 2 \theta$. The samples were prepared for analysis by dispersing the precipitates in acetone to form a thick suspension. This suspension was deposited on a zero background silicon single crystal plate and air dried at room temperature before collecting the XRD scans.

Samples after ADS and CPT, and a sample of synthetic 2-line ferrihydrite (as a base line) were particularly prepared to evaluate phase changes when aging at an elevated temperature. Samples were aged $24 \mathrm{~h}$ at $95^{\circ} \mathrm{C}$ and $14 \mathrm{~d}$ at $60{ }^{\circ} \mathrm{C}$ in a water bath before XRD analysis.

\section{EXPERIMENTAL RESULTS}

\subsection{Sorption edges in coprecipitation and adsorption experiments}

The experimental conditions in this study are summarized in Table 1. The aqueous solution chemistry data from pH titration experiments are depicted in Figs. 1-4. Both the conventional $\mathrm{pH}$ sorption edge diagrams (Figs. 2a and 3a) and the concentration versus $\mathrm{pH}$ diagrams (Figs. $2 \mathrm{~b}$ and $3 \mathrm{~b}$ ) are insensitive in portraying part of the sorption edges. The former is insensitive in the high $\mathrm{pH}$ range where metals sorption is near $100 \%$ (Karthikeyan et al., 1997), and the latter is insensitive in the low $\mathrm{pH}$ range where only a small percentage of metals are sorbed. Hence, it is instructive to plot both diagrams. The sigmoidal sorption edges of $\mathrm{Pb}$, characteristic of transition metal sorption, occurred between $\mathrm{pH} \sim 4$ and $\sim 6$ (Figs. 1-3). Although the Fe data are somewhat scattered, as is typical of $\mathrm{Fe}^{3+}$ experiments, it is clear that in CPT experiments most $\mathrm{Fe}^{3+}$ precipitated between $\mathrm{pH} 3$ and 4 (Fig. 4) before $\mathrm{Pb}^{2+}$ was removed from the aqueous solution. We noticed the apparent sorption of $<20 \%$ at pH lower than 4 (Fig. 1). This phenomenon has been observed previously in $\mathrm{Pb}^{2+}$ adsorption experiments (reviewed by Trivedi et al., 2003).

Although our three batches of CPT experiments differ in sorbate/sorbent ratios almost by ten folds, they have overlapping $\mathrm{pH}$ sorption edges (Fig. 1). In contrast, in the companion ADS experiments, an increase of sorbate/sorbent ratios displaced the sorption edge to higher $\mathrm{pH}$ (Fig. 3), a characteristic of surface complexation (Dzombak and Morel, 1990).

It appears that our coprecipitation experiment with a higher $\mathrm{Pb}: \mathrm{Fe}$ ratio (i.e., Batch $\mathrm{E}, \mathrm{Pb}: \mathrm{Fe}$ ratio of $0.11: 1.0$ ) removed percentages of $\mathrm{Pb}^{2+}$ from aqueous solution higher than that of ADS experiment with a similar $\mathrm{Pb}: \mathrm{Fe}$ ratio (Batch B, 0.13:1.0). Therefore, CPT is more efficient than ADS in removing $\mathrm{Pb}^{2+}$ from aqueous solutions at similar sorbate/sorbent ratios (Fig. 1). Moreover, the disparity of removal efficiency between $\mathrm{CPT}$ and ADS at similar sorbate/sorbent ratios increases at higher surface loading (Table 1, Fig. 1).

\subsection{X-ray diffraction data}

XRD patterns of precipitates from CPT experiments show a mixture of lepidocrocite and two additional broad peaks at a $d$-spacing of 0.154 and $0.27 \mathrm{~nm}$, respectively (Fig. 5). These two broad peaks are similar to those of synthetic and natural 2-line ferrihydrite (2LFh, Cornell and Schwertmann, 1996). The formation of lepidocrocite is likely due to the exclusion of $\mathrm{CO}_{2}$. Lepidocrocite is favored to form in the absence of carbonate. In the presence of $\mathrm{CO}_{2}$, however, goethite will form over lepidocrocite (Schwertmann and Taylor, 1972a,b; Schwertmann and Fitzpatrick, 1977; Schwertmann and Cornell, 1991; Cornell and Schwertmann, 1996). Lepidocrocite is relatively metastable with respect to its polymorph of goethite but the transformation to goethite is extremely slow at ambient temperature (Cornell and Schwertmann, 1996). The XRD identifications are consistent with TEM observations (see below).

Ferrihydrite, a common iron oxyhydroxide in waters, sediments, soils, mine wastes and acid mine drainage acts as an efficient scavenger for trace metals (including $\mathrm{Pb}^{2+}$ ) and radionuclides (Jambor and Dutrizac, 1998) due to its

Table 1

Titration experimental conditions. ${ }^{\mathrm{a}}$

\begin{tabular}{|c|c|c|c|c|c|c|c|c|c|c|}
\hline & $\begin{array}{l}\mathrm{HFO} \\
(\mathrm{g} / \mathrm{L})\end{array}$ & $\begin{array}{l}\mathrm{Fe} \\
(\mathrm{mM})\end{array}$ & $\begin{array}{l}\mathrm{Pb} \\
(\mathrm{mM})\end{array}$ & $\begin{array}{l}\mathrm{Fe}: \mathrm{Pb} \\
\text { total }\end{array}$ & $\begin{array}{l}\text { Total strong } \\
\text { sites }(\mathrm{mol})^{\mathrm{b}}\end{array}$ & $\begin{array}{l}\text { Total weak } \\
\text { sites }(\mathrm{mol})^{\mathrm{c}}\end{array}$ & $\begin{array}{l}\text { Surface } \\
\text { loading }(\%)^{\mathrm{d}}\end{array}$ & $\mathrm{pH}$ & $\begin{array}{l}\text { Eq time } \\
\text { (hr) }\end{array}$ & $\begin{array}{l}\text { Contact } \\
\text { method }\end{array}$ \\
\hline Batch $\mathrm{A}^{\mathrm{e}}$ & 0.47 & 5.25 & 0.37 & $1: 0.07$ & $2.62 \times 10^{-5}$ & $1.05 \times 10^{-3}$ & 35 & 4-6 & 24 & ADS \\
\hline Batch $\mathrm{B}^{\mathrm{e}}$ & 0.48 & 5.43 & 0.70 & $1: 0.13$ & $2.72 \times 10^{-5}$ & $1.09 \times 10^{-3}$ & 65 & 4-6 & 24 & ADS \\
\hline Batch C & 0.56 & 6.27 & 0.10 & $1: 0.02$ & $3.14 \times 10^{-5}$ & $1.25 \times 10^{-3}$ & 8 & $2.3-7$ & 24 & CPT \\
\hline Batch D & 0.51 & 5.77 & 0.37 & $1: 0.06$ & $2.89 \times 10^{-5}$ & $1.15 \times 10^{-3}$ & 31 & $2.3-7$ & 24 & $\mathrm{CPT}$ \\
\hline Batch E & 0.6 & 6.77 & 0.73 & $1: 0.11$ & $3.39 \times 10^{-5}$ & $1.35 \times 10^{-3}$ & 53 & $2.3-7^{\mathrm{f}}$ & 30 & $\mathrm{CPT}$ \\
\hline
\end{tabular}

\footnotetext{
${ }^{a}$ All studies used $\mathrm{Fe}\left(\mathrm{NO}_{3}\right)_{3}$ and $\mathrm{Pb}\left(\mathrm{NO}_{3}\right)_{2}$ with a background solution $10 \mathrm{mM} \mathrm{KNO}$.

b Total strong sites were calculated with 0.005 sites/mol (Dzombak and Morel, 1990).

c Total weak sites were calculated with 0.2 sites/mol (Dzombak and Morel, 1990).

${ }^{\mathrm{d}}$ Surface loading $=($ Total $\mathrm{Pb}$ concentration $) /($ Total strong sites + Total weak sites $)$.

e Ferrihydrite gel aged for $48 \mathrm{~h}$ subsequently used for adsorption studies within a further $48 \mathrm{~h}$.

${ }^{\mathrm{f}}$ A sample of $\mathrm{pH} 6$ is prepared for TEM study and another of $\mathrm{pH} 5.25$ is for EXAFS study.
} 


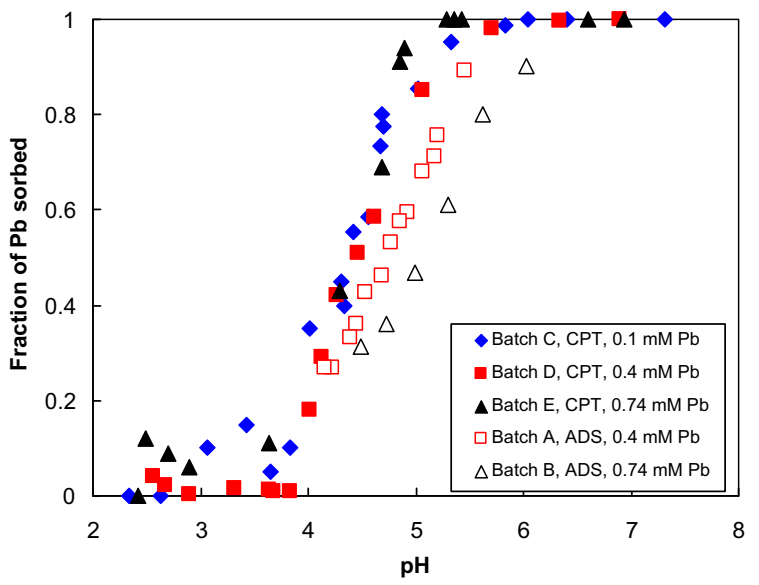

Fig. 1. Comparison of adsorption (Batches A and B) with coprecipitation experiments (Batches C, D, and E). $10 \mathrm{mM}$ $\mathrm{KNO}_{3}$ as background solution. Total $\mathrm{Fe}$ concentration varies from 5.25 to $6.77 \mathrm{mM}$ ).
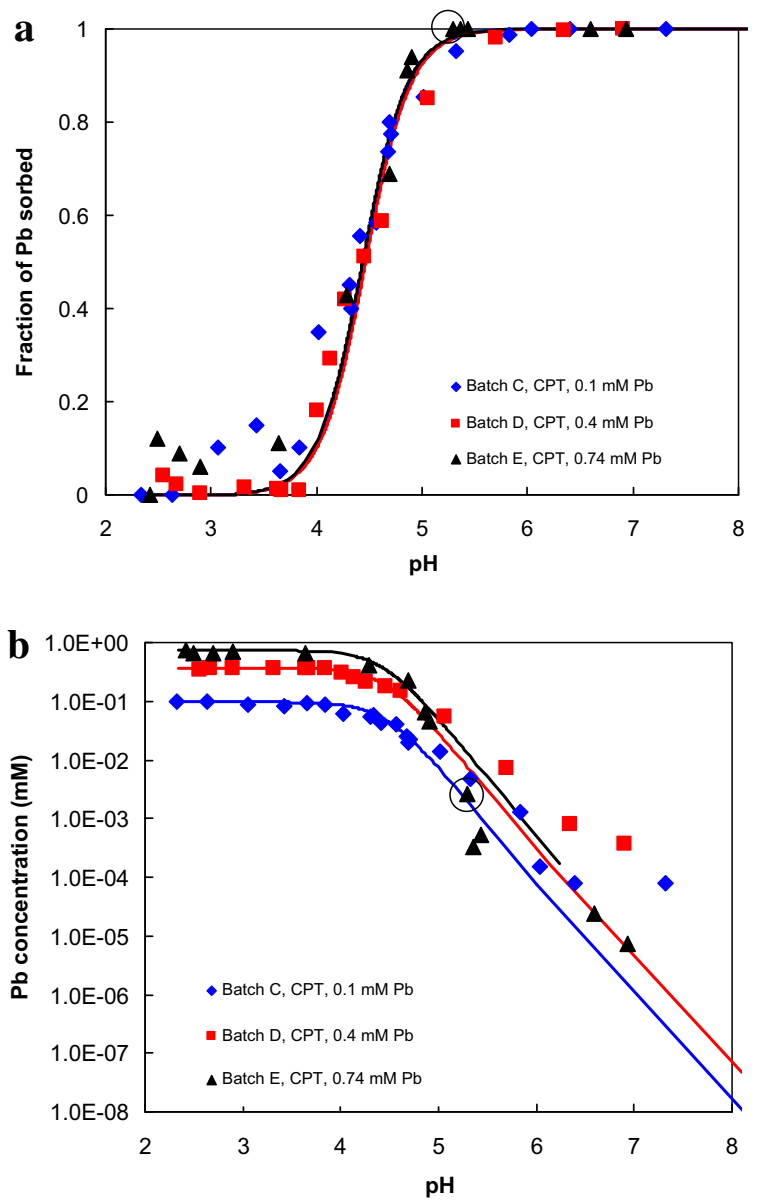

Fig. 2. Comparison of model calculations with experimental results. Solid symbols are results from CPT experiments. Experimental conditions are listed in Table 1. The lines were calculated with solid solution models. The circled point is the sample for EXAFS analysis reported by Kelly et al. (2008).
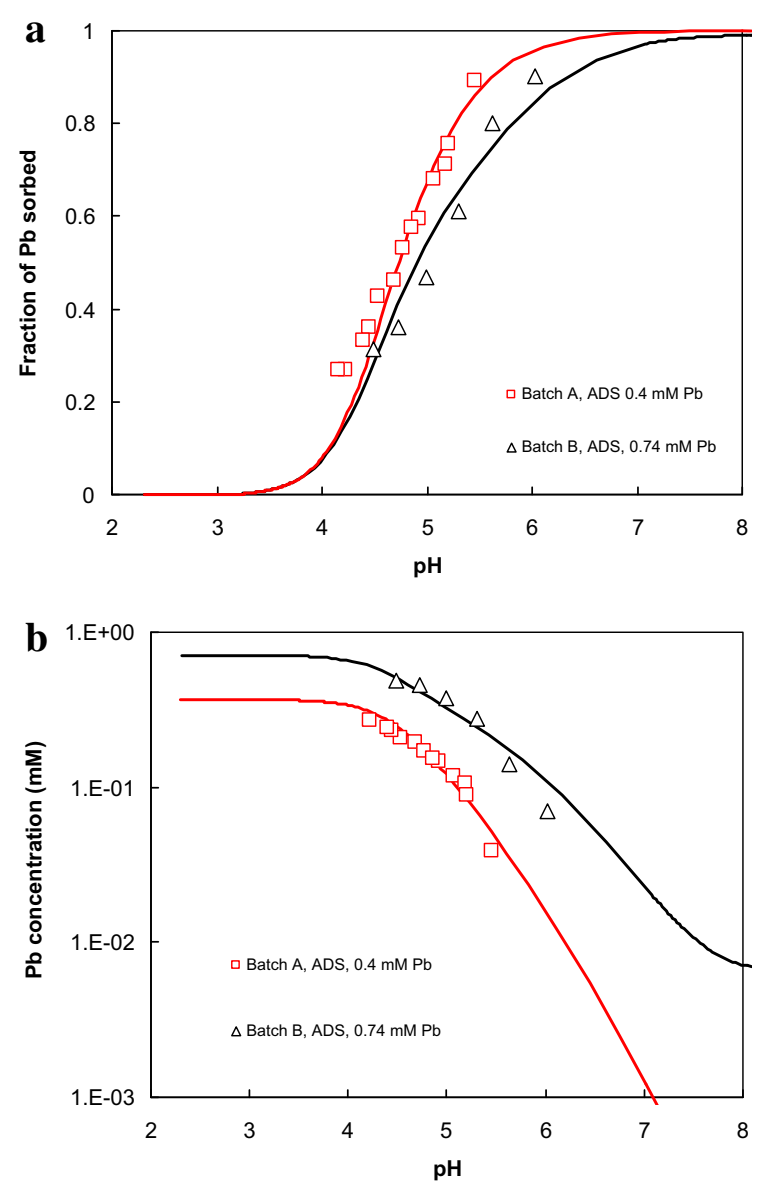

Fig. 3. Comparison of model calculations with experimental results. Symbols are results from ADS experiments. Experimental conditions are listed in Table 1. The lines were calculated with the model parameters from Dzombak and Morel (1990).

high specific surface area and reactivity (Dzombak and Morel, 1990; Cornell and Schwertmann, 1996). Ferrihydrite is commonly identified as "two-line" or "six-line" on the basis of the number of poorly defined, broadened maxima observed in XRD patterns (Cornell and Schwertmann, 1996). However, the latest literature suggests a single nano-crystallinity phase (Michel et al., 2007a,b). The domain sizes ranged from 2 to $6 \mathrm{~nm}$ (Michel et al., 2007a,b), which is consistent with the TEM results of this study (see below).

XRD patterns of precipitates from CPT and ADS experiments aged at $60{ }^{\circ} \mathrm{C}$ for $14 \mathrm{~d}$ and $95^{\circ} \mathrm{C}$ for $24 \mathrm{~h}$ were compared with synthesized 2-line ferrihydrite aged at both 95 and $22{ }^{\circ} \mathrm{C}$ for $24 \mathrm{~h}$ (Fig. 6), to investigate the phase transformation of precipitates during aging at elevated temperatures. Synthesized $2 \mathrm{LFh}$ aged $24 \mathrm{~h}$ at $22{ }^{\circ} \mathrm{C}$ is shown for comparison. Synthesized $2 \mathrm{LFh}$ aged at $95^{\circ} \mathrm{C}$ for $24 \mathrm{~h}$ shows a significant phase transformation from nanocrystalline ferrihydrite to crystalline goethite and hematite (Fig. 6). For solids from CPT and ADS experiments, the transformation from lepidocrocite and nano-crystalline ferrihydrite (Fig.5) to goethite and hematite seems to be retarded compared with synthesized $2 \mathrm{LFh}$ aged at the same temperature (Fig. 6). Goethite formation seems to be 

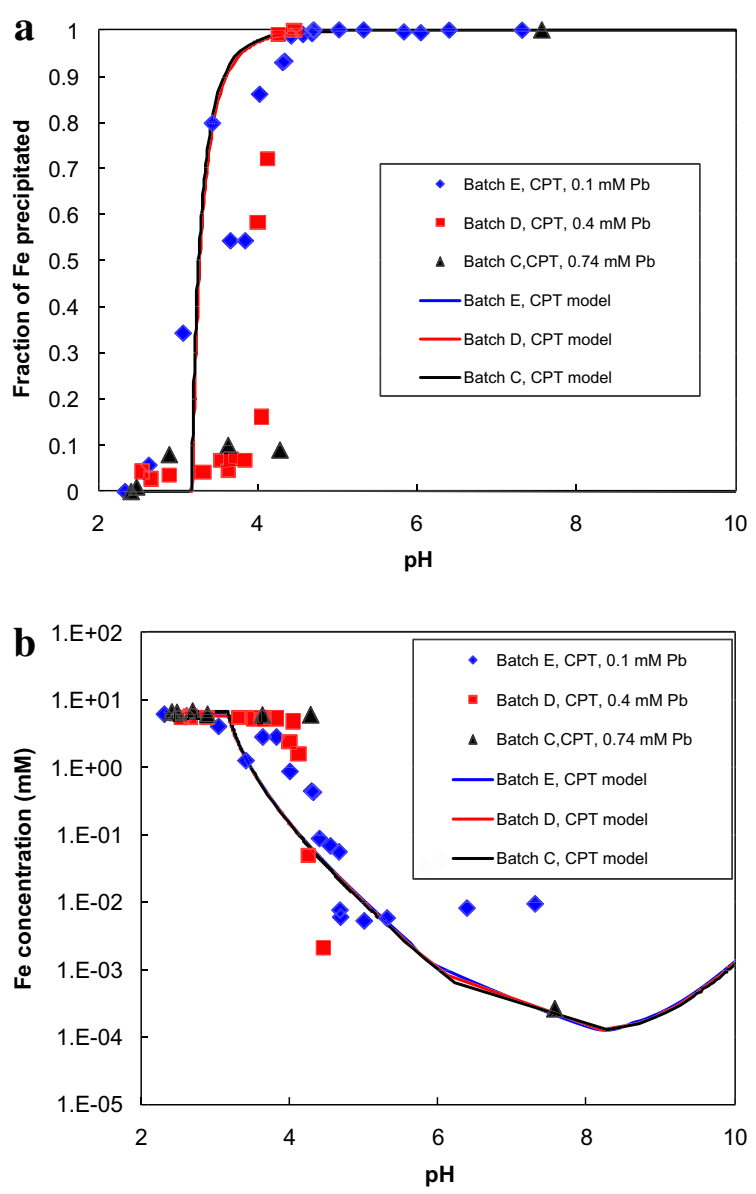

Fig. 4. Comparison of $\mathrm{Fe}^{3+}$ solubility data (symbols) with modeling calculations (lines). The solubility constant for amorphous $\mathrm{Fe}(\mathrm{OH})_{3}$ was from Wagman et al. (1982). Equilibrium constants of $\mathrm{Fe}^{3+}$ hydrolysis were from Nordstrom et al. (1990). Speciation calculation shows that $\mathrm{Fe}^{3+}-\mathrm{NO}_{3}^{-}$complexes were not significant during all experiments (equilibrium constant of $\mathrm{Fe}\left(\mathrm{NO}_{3}\right)_{2}$ from Wagman et al. (1982)). Numerical experiments show that change of the $\log K$ for iron oxyhydroxide does not change subsequent adsorption modeling.

suppressed in solids from ADS experiments aged at $60{ }^{\circ} \mathrm{C}$ for $14 \mathrm{~d}$ and $95^{\circ} \mathrm{C}$ for $24 \mathrm{~h}$. The retardation of phase transformation due to the presence of foreign ion impurity at the crystal growth site was also noted in Walton (1967). Waychunas et al. (1993) found that the presence of arsenate ions poisoned the surface of precipitating HFO, disrupting the normal crystallization process. Significant amounts of $2 \mathrm{LFh}$ remained in the $\mathrm{Pb}-\mathrm{Fe}$ coprecipitates aged at $60{ }^{\circ} \mathrm{C}$ for $14 \mathrm{~d}$ (Fig. 6) and even more $2 \mathrm{LFh}$ was retained in solids from the ADS experiments. This may explain the phenomenon that $\mathrm{Pb}$ and $\mathrm{Fe}$ are easier to be extracted from solids from the ADS experiments than $\mathrm{Pb}-\mathrm{Fe}$ coprecipitates after aging for $14 \mathrm{~d}$ at $60{ }^{\circ} \mathrm{C}$.

\subsection{High Resolution Transmission and Analytical Electron Microscopy}

High-Resolution Electron Microscopy of the solids from the CPT experiments $\left(22^{\circ} \mathrm{C}\right)$ shows two types of particles.
The first type is spherical, with diameters ranging from 2 to $6 \mathrm{~nm}$; the majority of the spheres being about $5 \mathrm{~nm}$ in diameter (Fig. 7). Fast Fournier Transformation (FFT) of the images (inset in Fig. 7) shows several $d$-spacings, whereas $2 \mathrm{LFh}$ have mainly two intense rings (Janney et al., 2000). These TEM results argue for a distorted $2 \mathrm{LFh}$ as compared to pure iron $2 \mathrm{LFh}$.

In addition to the small, spherical particles, dendrites or needle particles are also present. The needles are $8-20 \mathrm{~nm}$ across by $200-300 \mathrm{~nm}$ long, and are crystalline. High-resolution images show that the needles are composed of multiple domains 2-3 nm across (Fig. 8). FFT analysis of the image shows that the lattice of these small domains are parallel but slightly offset, suggesting that alignment is the mechanism of aggregation during crystal growth (Banfield et al., 2000; Penn et al., 2001).

No additional phases other than the iron oxyhydroxides mentioned above were found even though we examined many view fields and hundreds of particles. From this, we conclude that mechanical occlusion of fine particles (e.g., $\left.\mathrm{PbO}, \mathrm{Pb}(\mathrm{OH})_{2}, \mathrm{PbCO}_{3}\right)$ is unlikely to be the dominant mechanism of coprecipitation in our CPT experiments. It has been suspected that lead hydroxide may form as an artifact of localized high $\mathrm{pH}$ in the reactor during titration (Martinez and Mcbride, 1998), but TEM data show that this does not occur in our experiments. Geochemical modeling predicted, at high surface coverage, e.g., $>10 \%$, that $\mathrm{Pb}^{2+}$ may form a surface precipitate, which resembles a solid solution (Farley et al., 1985). In our Batch E experiments, the $\mathrm{Fe}: \mathrm{Pb}$ molar ratio is $1: 0.11$. When all the $\mathrm{Pb}^{2+}$ is sorbed, about $53 \%$ of the surface sites are covered with $\mathrm{Pb}^{2+}$, according to the surface site densities recommended by Dzombak and Morel (1990). However, high-resolution lattice images of our samples do not show a distinctly different phase at the edges of the particles (Figs. 7 and 8).

STEM/EDX analysis shows that the clusters contain Fe, $\mathrm{O}$, and $\mathrm{Pb}$, with a ratio of $\mathrm{Pb}$ to $\mathrm{Fe}$ close to that from the mass balance of solution chemistry in the samples examined. Over 50 EDX spectra also showed no Pb-concentrated areas, indicating that the $\mathrm{Pb}$ is homogeneously distributed (Fig. 9). The probe size for the analysis was $0.5 \mathrm{~nm}$ at $1 \mathrm{nA}$ of beam current, but the specimen preparation did not completely separate the individual grains and therefore most analyses sampled overlapped particles.

\subsection{Desorption experiments at room temperature}

The amount of $\mathrm{Pb}^{2+}$ extracted from the $\mathrm{Pb}$-loaded sorbents increased rapidly with increasing strength of EDTA at low EDTA concentrations for $1 \mathrm{~h}$ contact time, but leveled off at an EDTA concentration of $>\sim 0.003 \mathrm{M}$. Significantly more $\mathrm{Pb}^{2+}$ was extracted from the sorbents used in the adsorption experiments than $\mathrm{Pb}-\mathrm{Fe}$ coprecipitates when the concentrations of EDTA are less than $0.002 \mathrm{M}$ (Fig. 10). Caution must be exercised regarding potential underestimation of the reported fraction of $\mathrm{Pb}$ or $\mathrm{Fe}$ extracted/dissolved in extraction experiments because of possible loss of solids during separation.

$\mathrm{Pb}^{2+}$ may be desorbed from the sorbents by both forming EDTA- $\mathrm{Pb}^{2+}$ aqueous complexes and by dissolving the 


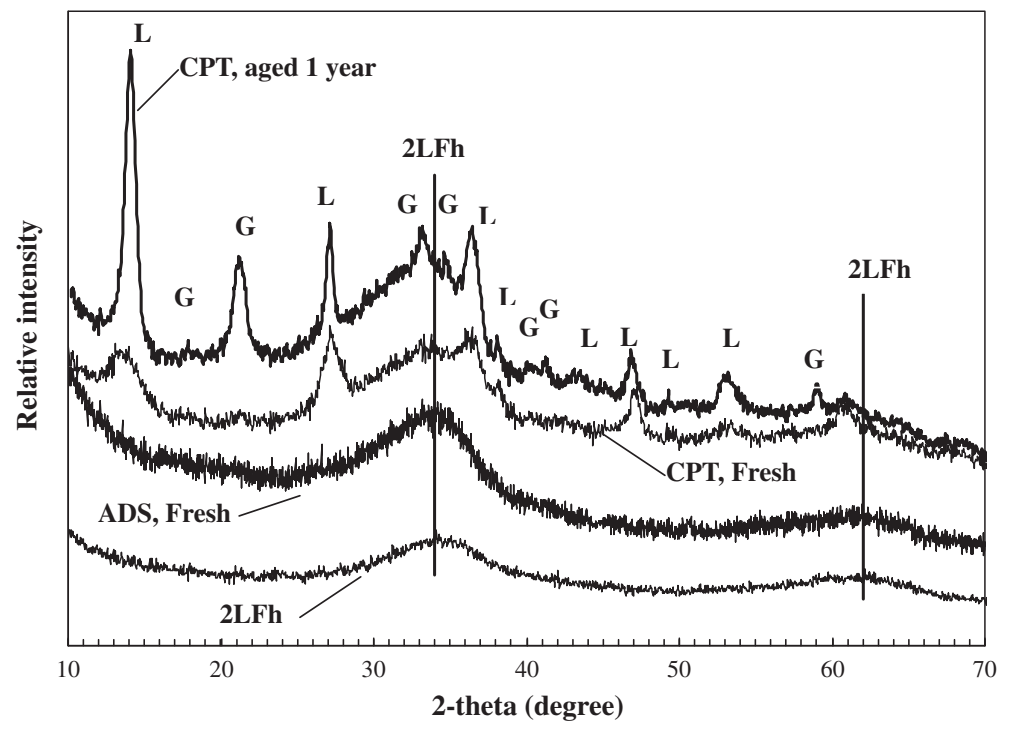

Fig. 5. X-ray diffraction spectrum for precipitates after CPT experiments in comparison with precipitates after ADS experiments (at $22{ }^{\circ} \mathrm{C}$ ). Precipitates aged 1 year after CPT experiments were more ordered than freshly precipitated ones. Lepidocrocite (ICDD: 44-1415) and goethite (ICDD: 28-0713) are identified as Fe phases in addition to 2-line ferrihydrite in precipitates after CPT experiments. The XRD pattern of precipitates after ADS experiments are almost entirely amorphous and look similar to that of synthesized 2-line ferrihydrite; no crystalline Fe or $\mathrm{Pb}$ phases were observed.

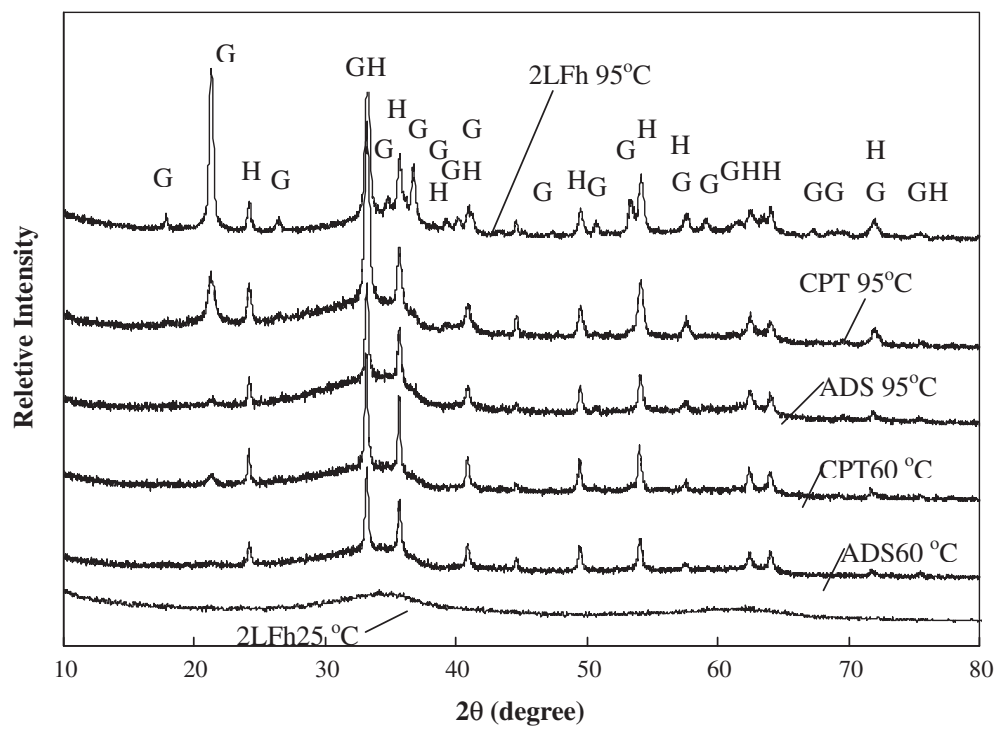

Fig. 6. Comparison of precipitates of ADS (aged $24 \mathrm{~h}$ at $95{ }^{\circ} \mathrm{C}$ or $14 \mathrm{~d}$ at $60{ }^{\circ} \mathrm{C}$ ), CPT (aged $24 \mathrm{~h}$ at $95{ }^{\circ} \mathrm{C}$ or $14 \mathrm{~d}$ at $60{ }^{\circ} \mathrm{C}$ ), and synthesized 2 line ferrihydrite (aged $24 \mathrm{~h}$ at $95^{\circ} \mathrm{C}$ ). Goethite $\left(\mathrm{FeO}(\mathrm{OH})\right.$, ICDD 28-0713) and hematite ( $\mathrm{Fe}_{2} \mathrm{O}_{3}$, ICDD: 89-0599) were identified as the main Fe crystalline phases. XRD pattern of synthesized 2-line ferrihydrite aged $24 \mathrm{~h}$ at $22{ }^{\circ} \mathrm{C}$ was shown as a reference for the position and intensity of amorphous phases.

iron oxyhydroxides substrate. Therefore, the relationship between dissolved $\mathrm{Fe}^{3+}$ and $\mathrm{Pb}^{2+}$ is indicative of incorporation mechanisms for $\mathrm{Pb}^{2+}$ in the sorbents. Fig. 11 shows a linear relationship between the $\mathrm{Pb}$ extracted and $\mathrm{Fe}$ dissolved for CPT solids with EDTA concentrations between 0.0003 and $0.01 \mathrm{M}$ and a contact time of $1 \mathrm{~h}$, but a parabolic relationship for ADS solids. The different patterns of $\mathrm{Pb}$ versus $\mathrm{Fe}$ relationships for ADS and CPT suggest that ADS and CPT are controlled by different mechanisms. Calculations (Appendix A) show that a 6-nm particle (assuming perfect periodic stacking) has $\sim 20 \%$ of Fe atoms at the surface. About $90 \%$ of $\mathrm{Pb}$ was extracted when only about $15 \%$ of $\mathrm{Fe}$ was dissolved for sorbents from ADS experiments. This indicates that $\mathrm{Pb}$ is mainly bound to the sorbent surfaces. In contrast, dissolution of the same amount of $\mathrm{Fe}$ only released about half the solid-bound $\mathrm{Pb}^{2+}$ into the solution, suggesting that surface bounding is not the principal mechanism for CPT contact method (Fig. 11). If enhanced $\mathrm{Pb}$ removal by the CPT method was simply attributable to an increase in surface area or site 


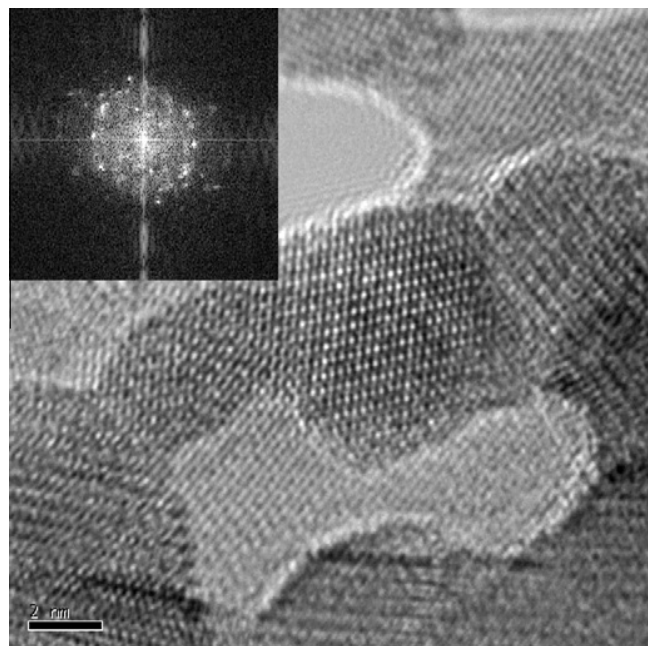

Fig. 7. HRTEM image of $\mathrm{Fe}^{3+}$ and $\mathrm{Pb}^{2+}$ coprecipitates with spherical shape. Each particle is a single crystallite. Patterns are lattice images.

density, more $\mathrm{Pb}$ should be released in the CPT system compared to the solids from the ADS system.

\subsection{Extraction experiments after the sorbents were aged at elevated temperature $\left(60{ }^{\circ} \mathrm{C}\right)$}

Fig. 12 shows the results of extraction experiments after the sorbents were aged at $60{ }^{\circ} \mathrm{C}$ for 14 days. As shown previously, XRD patterns show that the aged sorbents are a mixture of goethite, hematite, and 2LFh. The fractions of $\mathrm{Pb}$ desorbed in the ADS case increase parabolically with increasing EDTA concentrations and leveled off at fractions $\sim 0.6$. The desorbed $\mathrm{Pb}^{2+}$ also increases parabolically with increasing Fe concentrations (Fig. 12b). These results indicate that $\mathrm{Pb}^{2+}$ was mainly associated with the outer layer in the aged solids of ADS. For aged sorbents from CPT experiments, there are much weaker correlations between $\mathrm{Pb}^{2+}$ concentrations and $\mathrm{Fe}$ concentrations.

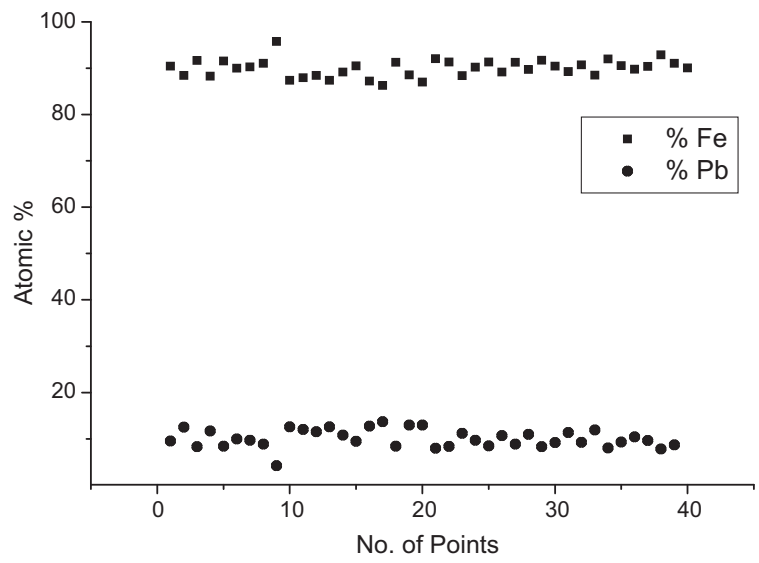

Fig. 9. Fifty measurements for composition analysis by Energy Dispersive $\mathrm{X}$-ray for the ratio of $\mathrm{Fe}$ and $\mathrm{Pb}$ in atomic $\%$.

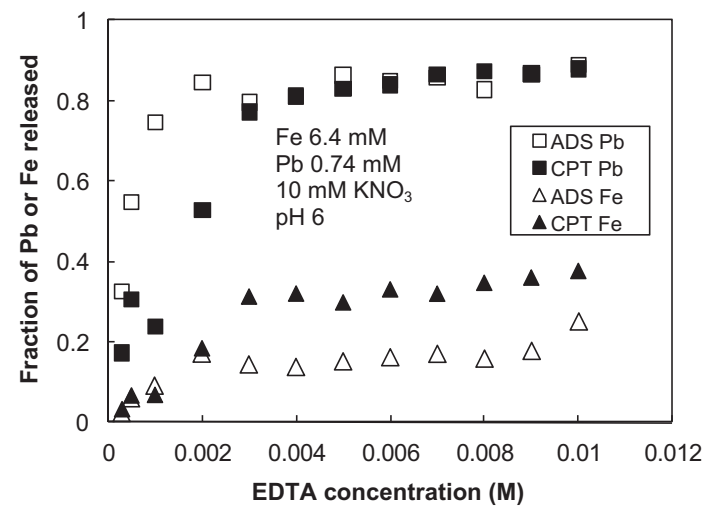

Fig. 10. Fraction of $\mathrm{Pb}$ extracted after ADS and CPT experiments as a function of different EDTA concentration (room temperature, $\sim 22^{\circ} \mathrm{C}$ ). The contact time is $1 \mathrm{~h}$.

Even with increasing EDTA concentrations, about 40 $50 \%$ of $\mathrm{Pb}$ was retained with the CPT solids (residual) after the extraction experiments. This coincides with the leveling
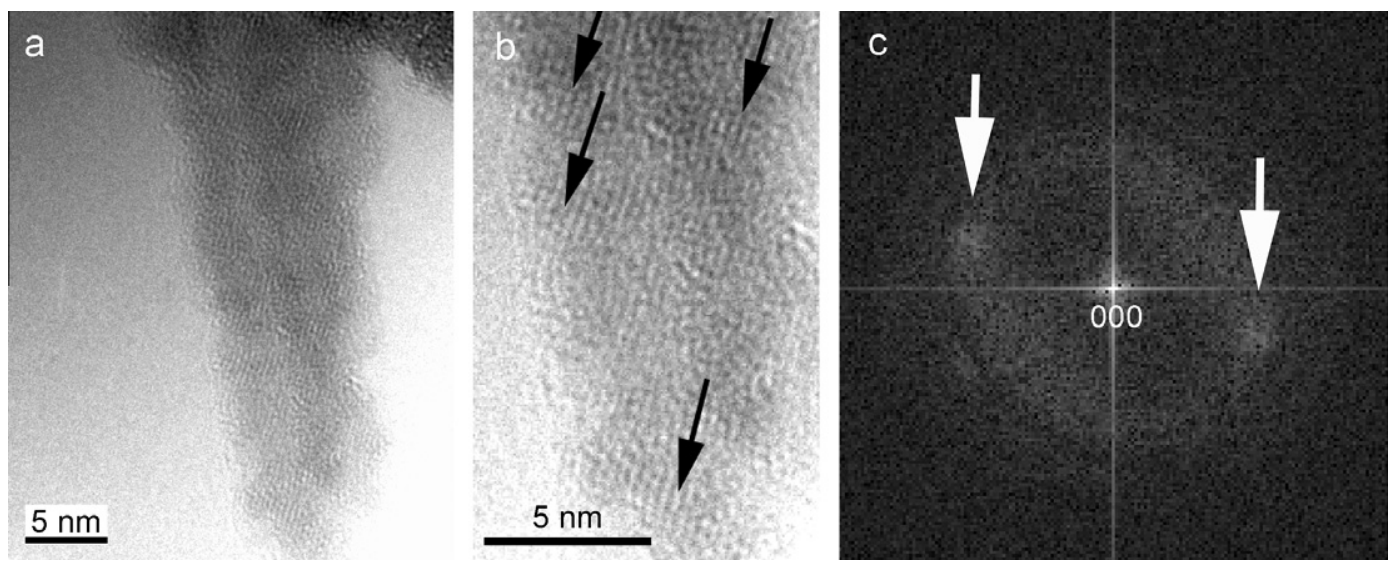

Fig. 8. HRTEM image of $\mathrm{Pb}^{2+}$ bearing iron oxyhydroxide needle. (a) and (b) HRTEM images. The tip of the needle is composed of domains with slightly different orientations. Black arrows indicate the orientation of lattice images; and (c) fast Fourier transform (FFT) images of the tip of a Pb-bearing iron oxyhyroxide needle. The FFT image shows two broad spots (white arrows), suggesting that each small domain has a similar but slightly different orientations. 


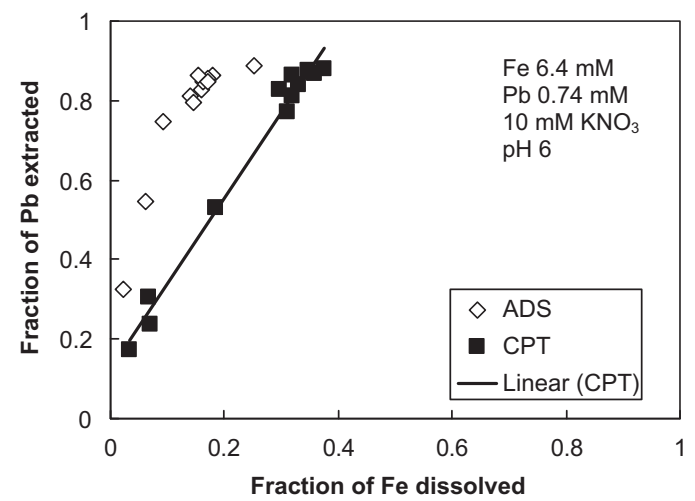

Fig. 11. Fraction of $\mathrm{Pb}$ extracted as a function of fraction of $\mathrm{Fe}$ dissolved contacting with different concentration of EDTA for $1 \mathrm{~h}$ (at room temperature, $\sim 22^{\circ} \mathrm{C}$ ). $\mathrm{Pb}$ extracted versus Fe dissolved of coprecipitation precipitates showed a linear relationship, but extraction from adsorption precipitates did not.
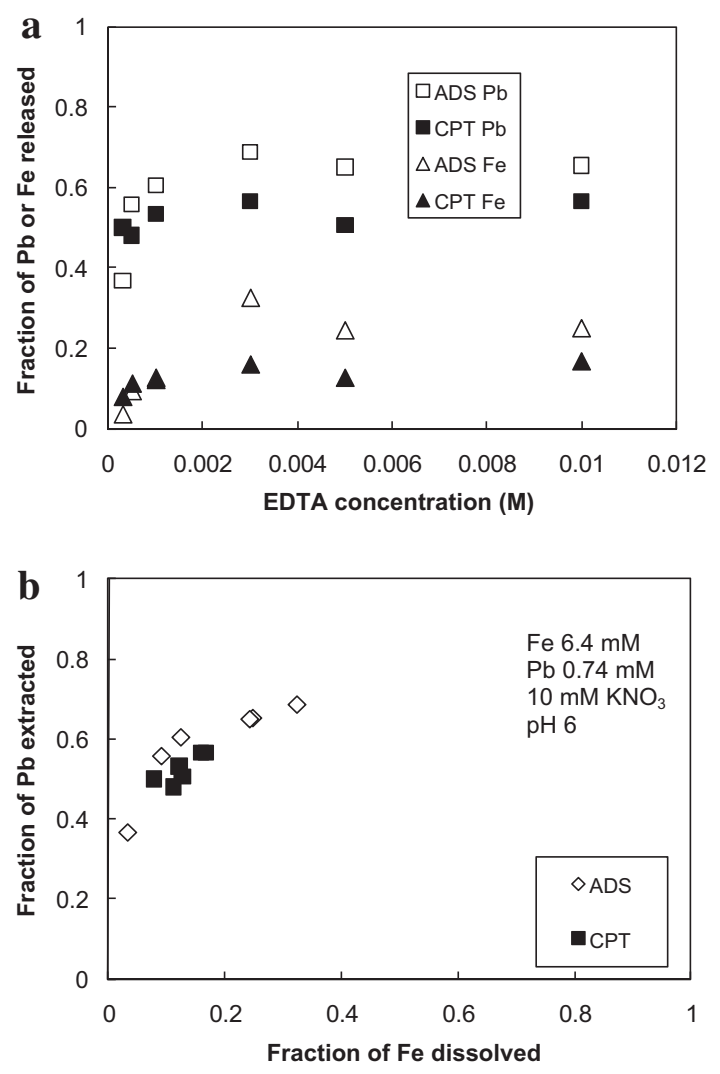

Fig. 12. (a) Dissolved $\mathrm{Pb}$ and $\mathrm{Fe}$ concentrations as a function of EDTA concentrations. The contact time is $1 \mathrm{~h}$. The solids were aged at $60{ }^{\circ} \mathrm{C}$ for 14 days before the extraction experiments. XRD patterns show a mixture of $2 \mathrm{LFh}$, hematite, and goethite. (b) Fraction of $\mathrm{Pb}$ versus $\mathrm{Fe}$ from the same experiments.

off of dissolved Fe concentrations - crystalline goethite and hematite do not dissolve more with increasingly concentrated EDTA solutions (Fig. 12a). This correlation between $\mathrm{Pb}$ and $\mathrm{Fe}$ may suggest that $\mathrm{Pb}$ might be partly incorporated into the hematite and goethite structure. In the processes of transformation to more ordered structures (e.g., hematite or goethite), part of the $\mathrm{Pb}$ may be expelled from the inside of the $\mathrm{Fe}$ structure and become mobile again (Ford et al., 1997). This explains why $\sim 50 \%$ of $\mathrm{Pb}$ was easily be extracted even at low EDTA concentration (0.0003 M).

\section{GEOCHEMICAL MODELING}

We evaluated whether surface complexation models and solid solution models can fit the experimentally measured sorption edges. The geochemical modeling code PHreeQC (Parkhurst and Appello, 1999) was used for the simulation. The standard states for the solids are defined as unit activity for pure solids at the temperature and pressure of interest. The standard state for water is the unit activity of pure water. For aqueous species other than $\mathrm{H}_{2} \mathrm{O}$, the standard state is the unit activity of the species in a hypothetical one molal ideal solution referenced to infinite dilution at the temperature and pressure of interest. Standard states for the surface sites are the unit activity of a completely unsaturated surface at the pressure and temperature of interest and for surface species, the unit activity on a completely saturated surface with zero potential with reference to infinite dilution at the $P, T$ of interest (Sverjensky, 2003). The thermodynamic properties used in the simulations are listed in Table 2.

\subsection{Surface complexation models (SCM)}

The generalized diffuse layer model (Dzombak and Morel, 1990) was used for modeling surface adsorption in the proposed study. Other electrostatic surface adsorption models have been proposed (e.g., constant capacitance and triple layer models) but all electrostatic models can describe limited experimental sorption data sets (Westall and Hohl, 1980; Venema et al., 1996). Models that use one site type generally require more than one complex species (e.g., Dyer et al., 2003). Dzombak and Morel (1990) provides a consistent theory and a large database of self-consistent surface complexation constants for adsorption on hydrous ferric oxides. They reviewed $\mathrm{Pb}^{2+}$ adsorption experimental (ADS) data and developed a two-site model for $\mathrm{Pb}^{2+}$ adsorption, a "weak" site and a "strong" site, through the reactions:

$\equiv \mathrm{Fe}^{\mathrm{s}} \mathrm{OH}^{\mathrm{o}}+\mathrm{Pb}^{2+}=\equiv \mathrm{Fe}^{\mathrm{s}} \mathrm{OPb}^{+}+\mathrm{H}^{+}$

$\equiv \mathrm{Fe}^{\mathrm{w}} \mathrm{OH}^{\mathrm{o}}+\mathrm{Pb}^{2+}=\equiv \mathrm{Fe}^{\mathrm{w}} \mathrm{OPb}^{+}+\mathrm{H}^{+}$

where the symbol "” denotes the surface site or functional group. Intrinsic surface complexation constants for reactions (1) and (2), derived from systematic evaluation of the ADS data by Dzombak and Morel (1990), and $\mathrm{Pb}^{2+}$ hydrolysis constants are listed in Table 2. Other surface properties are listed in Table 3. The generalized diffuse two-layer model fit our ADS experimental data (Fig. 3) well. As expected, the SCM predicts shifts of $\mathrm{pH}$ sorption edges with different $\mathrm{Pb}: \mathrm{Fe}$ ratios.

However, the same Dzombak and Morel's (1990) SCM model grossly underestimated sorption edges measured in 
Table 2

Equilibrium constants used in modeling.

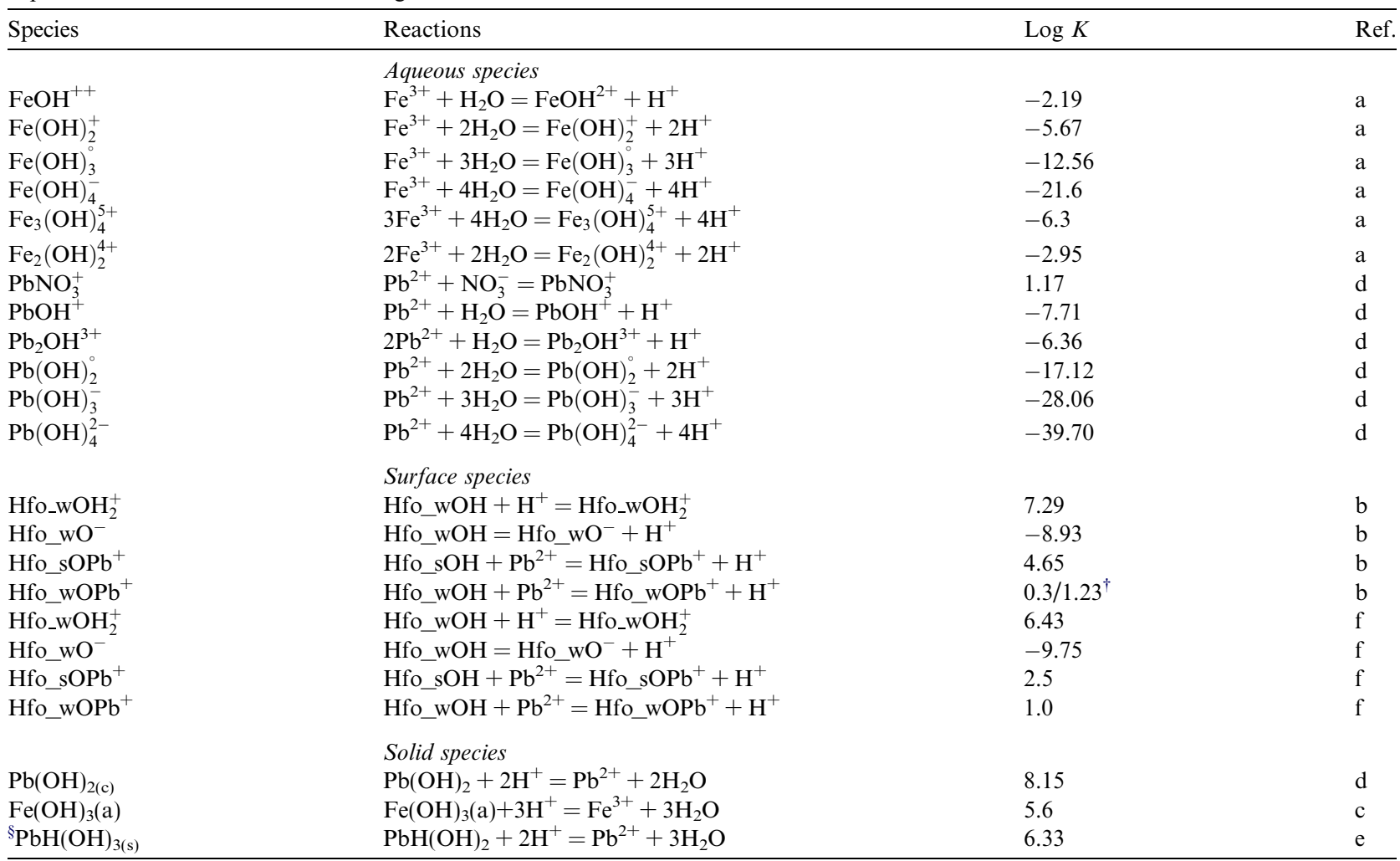

a: Nordstrom et al. (1990); b: Dzombak and Morel (1990); c: Wagman et al. (1982); d: Ball and Nordstrom (1991); e: retrieved from experimental data in this study; f: Dyer et al. (2003).

$\S$ Solid solution components.

$\dagger$ Ainsworth et al. (1994).

Table 3

Surface properties for HFO used in this study.

\begin{tabular}{|c|c|c|c|}
\hline \multicolumn{2}{|l|}{ Properties } & \multicolumn{2}{|l|}{ Values } \\
\hline \multicolumn{4}{|c|}{ Site density $(\mathrm{mol} / \mathrm{mol} \mathrm{Fe})$} \\
\hline \multicolumn{4}{|l|}{$N_{\mathrm{s}}$} \\
\hline Weak (w) & $0.2^{\mathrm{a}}$ & $0.9^{\mathrm{b}}$ & $0.2^{\mathrm{c}}$ \\
\hline Strong (s) & $0.005^{\mathrm{a}}$ & $0.0225^{\mathrm{b}}$ & $0.005^{\mathrm{c}}$ \\
\hline Surface area $\left(\mathrm{m}^{2} / \mathrm{g}\right)$ & $600^{\mathrm{a}}$ & $600^{\mathrm{b}}$ & $600^{\mathrm{c}}$ \\
\hline Molwt (g/mol) & $89^{\mathrm{a}}$ & $89^{b}$ & $89^{c}$ \\
\hline
\end{tabular}

the CPT experiments (Fig. 13). Some workers found the need for different, actually stronger, binding constants to fit their own adsorption experimental data (Ainsworth et al., 1994; Dyer et al., 2003). Dyer et al. (2003) also developed a triple layer model, in which they used bidentate $\mathrm{Pb}^{2+}$ complexes. The increase of the complexation constant values sharpens the sorption edge and lowers the concentrations of $\mathrm{Pb}^{2+}$, which will move the sorption edge to a lower $\mathrm{pH}$. As shown below, one hypothesis to explain CPT from ADS is that CPT represents greater binding strength because of multiple surface sites. We tested this hypothesis by increasing the complexation constants for the weak site to the values proposed by Ainsworth et al. (1994) and Dyer et al. (2003). However, the SCM still did not fit the CPT data.

We then increased the site density while keeping a high complexation constant for the weak site. With a higher site density $N_{\mathrm{s}}(0.9 \mathrm{~mol}$ sites $/ \mathrm{mol} \mathrm{Fe}$ versus $0.2 \mathrm{~mol}$ sites $/ \mathrm{mol} \mathrm{Fe}$ for the weak site and 0.0225 versus 0.005 for strong site in the Dzombak and Morel model), the model matches well with our lower $\mathrm{Pb}: \mathrm{Fe}$ ratio experiments (Batches $\mathrm{C}$ and $\mathrm{D})$, but not with the high $\mathrm{Pb}: \mathrm{Fe}$ ratio experiment (Batch E) (Fig. 13).

\subsection{Solid solution models}

Modeling the coprecipitation of $2 \mathrm{LFh}$ as a solid solution formation process is challenging due to the lack of knowledge regarding solid solution stoichiometry. Furthermore, the stoichiometry of $2 \mathrm{LFh}$ is controversial. Recently, Michel et al. (2007a) proposed a structural formulae of $\mathrm{Fe}_{10} \mathrm{O}_{14}(\mathrm{OH})_{2}$ and the ideal form contains $20 \%$ tetrahedrally and $80 \%$ octahedrally coordinated $\mathrm{Fe}$, which is further modified with a disordered model (Michel et al., 2010). Our EXAFS work shows that incorporated $\mathrm{Pb}$ is mostly octahedrally coordinated. The EXAFS data also show that the much larger ionic radius of $\mathrm{Pb}^{2+}$ as compared to that of $\mathrm{Fe}^{3+}$ shift the $\mathrm{Pb}^{2+}$ octahedral away from the $\mathrm{Fe}$ 

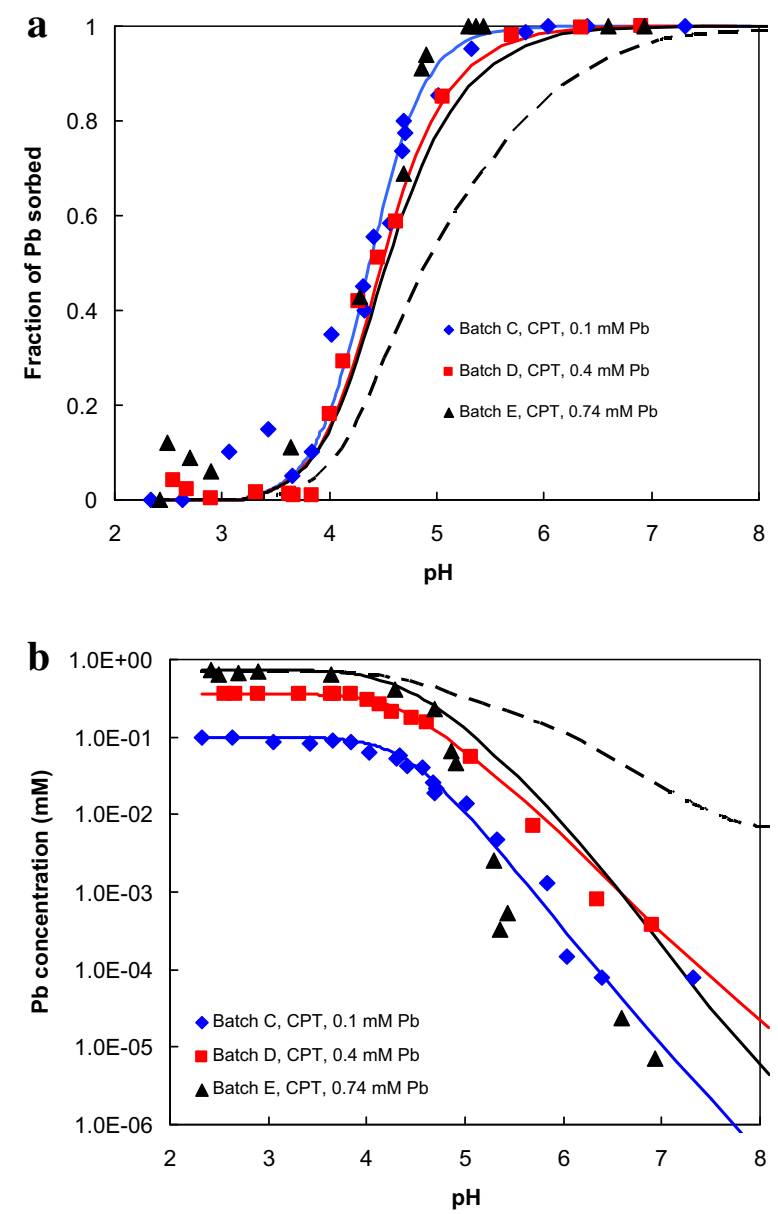

Fig. 13. Modeling coprecipitation experiments with surface complexation models. Solid lines are models with site densities values of $0.9 \mathrm{~mol} / \mathrm{mol} \mathrm{Fe}$ for weak sites and 0.0225 for strong sites and log $\mathrm{Ks}$ from Dyer et al. (2003), see Table 2. Dashed lines were generated for the $0.74 \mathrm{mM} \mathrm{Pb}$ experiment from parameters in Dzombak and Morel (1990) $(0.2 \mathrm{~mol} / \mathrm{mol} \mathrm{Fe}$ for weak sites and 0.005 for strong sites, and their $\log K_{\mathrm{s}}$ ).

octahedra sheet. Given the lack of solid solution stoichiometry, it is difficult to fit the experimental data to a solid solution model. Rather, it is more prudent to use solid solution models to examine the characteristics of $\mathrm{pH}$ sorption edges if this incorporation mechanism is dominant.

For solid solution modeling, we assumed that the precipitated iron oxyhydroxide has a nominal formula of $\mathrm{Fe}(\mathrm{O}-$ $\mathrm{H})_{3(\mathrm{am})}$ (Dzombak and Morel, 1990). CPT was modeled as an ideal solid solution. A solid solution model takes the stoichiometry of

$$
\begin{aligned}
& \mathrm{Fe}(\mathrm{OH})_{3(\mathrm{~s})}+3 \mathrm{H}^{+}=\mathrm{Fe}^{3+}+3 \mathrm{H}_{2} \mathrm{O} \\
& \mathrm{PbH}(\mathrm{OH})_{3(\mathrm{~s})}+2 \mathrm{H}^{+}=\mathrm{Pb}^{2+}+3 \mathrm{H}_{2} \mathrm{O}
\end{aligned}
$$

Here, we assume that the one-for-one substitution of $\mathrm{Pb}^{2+}$ for $\mathrm{Fe}^{3+}$ is compensated by an addition of $\mathrm{H}^{+}$into the crystalline structure or a replacement of $\mathrm{OH}^{-}$for $\mathrm{O}^{2-}$ (e.g., Waychunas et al., 2002). When a Henrian standard state is defined as hypothetical pure $\mathrm{PbH}(\mathrm{OH})_{3(\mathrm{~s})}$ end members of the solid solution with an $\mathrm{Fe}(\mathrm{OH})_{3(\mathrm{am})}$ structure, extrapolated from the infinitely dilute solution regions where Henry's law is obeyed, and a Raoultian standard state remains for the $\mathrm{Fe}(\mathrm{OH})_{3}$ end member, the activity coefficients for both $\mathrm{Fe}(\mathrm{OH})_{3}$ and $\mathrm{PbH}(\mathrm{OH})_{3(\mathrm{~s})}$ are unity in the dilute solution regions where Henry's law is obeyed for the tracer (Ganguly and Saxena, 1987).

The above solid solution model was used to model our $\mathrm{Fe}-\mathrm{Pb} \mathrm{CPT}$ experiments. The solid solution model successfully predicts the $\mathrm{Pb}^{2+}$ concentrations in the low $\mathrm{pH}$ range $(\mathrm{pH}<5)$ on the concentration - $\mathrm{pH}$ diagram (Fig. 2b) but predict more $\mathrm{Pb}^{2+}$ partitioned into the solid solution than experimental data at higher $\mathrm{pH}$ values (Fig. 2b). The real benefit of solid solution modeling is the theoretical prediction of invariant $\mathrm{pH}$ sorption edges in experiments with different $\mathrm{Pb}: \mathrm{Fe}$ ratios, regardless of the specific solid solution models, as opposed to variant $\mathrm{pH}$ sorption edges in the case of adsorption.

Whether formation of a solid solution can be the dominant coprecipitation mechanism in our experiment can also be tested with the calculation of the partitioning coefficient which is defined as,

$K_{\mathrm{D}}=\left(\frac{X_{\mathrm{Pb}}}{1-X_{\mathrm{Pb}}}\right) / \frac{a_{\mathrm{Pb}^{2+}}}{a_{\mathrm{Fe}^{3+}}}$

where $X_{\mathrm{Pb}}$ is the mole fraction of $\mathrm{Pb}^{2+}$ in the solid solution,

$X_{\mathrm{Pb}}=M_{\mathrm{Pb}} /\left(M_{\mathrm{Pb}}+M_{\mathrm{Fe}}\right)$

where $M$ stands for moles of $\mathrm{Pb}$ or $\mathrm{Fe}$ in solids per kgw of solution. $K_{\mathrm{D}}$ for the three coprecipitation experiments were calculated and plotted in Fig. 14. $\mathrm{Pb}$ mole fractions were calculated from the mass balance of $\mathrm{Pb}^{2+}$ and $\mathrm{Fe}^{3+}$ remained in solutions at the end of the experiments, and activities of $\mathrm{Pb}^{2+}$ and $\mathrm{Fe}^{3+}$ were calculated from speciation modeling.

Combining Eqs. (3) and (4) leads to the overall solid solution formation reaction,

$\mathrm{Fe}(\mathrm{OH})_{3 \mathrm{ss}}+\mathrm{Pb}^{2+}+\mathrm{H}^{+}=\mathrm{PbH}(\mathrm{OH})_{3 \mathrm{ss}}+\mathrm{Fe}^{3+}$

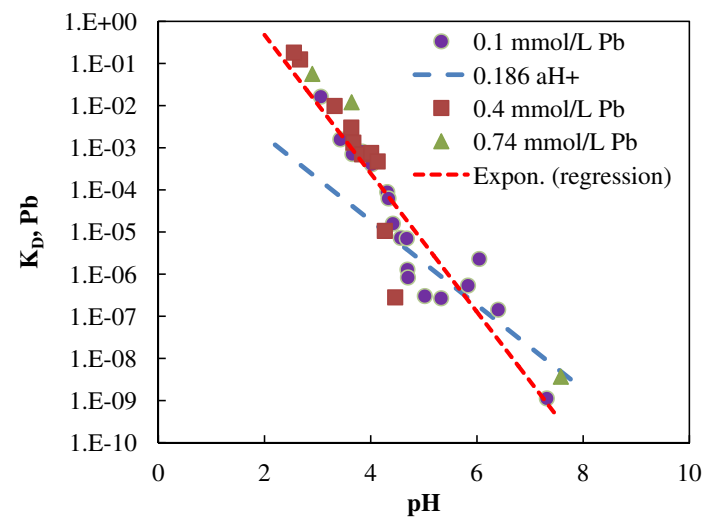

Fig. 14. $K_{\mathrm{D}, \mathrm{Pb}}$ of three sets of coprecipitation experiments (Batches $\mathrm{C}, \mathrm{D}$ and $\mathrm{E}$ ) as a function of $\mathrm{pH}$. The three sets of data with different $\mathrm{Pb}$ :Fe ratios show a linear relationship of $\log K_{\mathrm{D}, \mathrm{Pb}}$ versus $\mathrm{pH}$ (red dashed line). (For interpretation of the references to color in this figure legend, the reader is referred to the web version of this article.) 
and the corresponding mass action equation,

$K_{7}=\frac{a_{\mathrm{Fe}^{3+}} a_{\mathrm{PbH}(\mathrm{OH})_{3 \mathrm{ss}}}}{a_{\mathrm{Pb}^{2+}} a_{\mathrm{Fe}(\mathrm{OH})_{3 s \mathrm{ss}}} a_{\mathrm{H}^{+}}}$

The equilibrium constants for reactions (3) and (4) can be written as,

$K_{3}=\frac{a_{\mathrm{Fe}^{3+}} a_{\mathrm{H}_{2} \mathrm{O}}^{3}}{a_{\mathrm{Fe}(\mathrm{OH})_{3 \mathrm{ss}}} a_{\mathrm{H}^{+}}^{3}}$

$K_{4}=\frac{a_{\mathrm{Pb}^{2+}} a_{\mathrm{H}_{2} \mathrm{O}}^{3}}{a_{\mathrm{PbH}(\mathrm{OH})_{3 s s}} a_{\mathrm{H}^{+}}^{2}}$

and we have the relationship,

$K_{7}=K_{3} / K_{4}$

From the $\log K$ values in Table 2, we have

$K_{7}=K_{3} / K_{4}=10^{5.6} / 10^{6.33}=10^{-0.73}=0.186$

Assuming ideal mixing in the solid solution and substituting Eq. (5) into Eq. (8), we have,

$K_{\mathrm{D}}=K_{7} \times a_{\mathrm{H}^{+}}=0.186 \times a_{\mathrm{H}^{+}}$

or

$\log K_{\mathrm{D}}=-0.73-\mathrm{pH}$

Eq. (14) shows that if solid solution formation is the dominant mechanism for $\mathrm{Pb}-\mathrm{Fe}$ coprecipitation, we should see a linear relationship between $\log K_{\mathrm{D}}$ and $\mathrm{pH}$. Indeed, Fig. 14 reveals a linear trend for all three coprecipitation experiments. However, the slope is not one as in Eq. (14). That suggests that the nominal chemical stoichiometry we used for the solid solution in Eqs. (3), (4), and (7) do not represent the stoichiometry of the solid solution.

Linear regression of $\log K_{\mathrm{D}}$ versus $\mathrm{pH}$ generated a relationship,

$\log K_{\mathrm{D}}=2.963-1.643 \mathrm{pH}$

With a $R^{2}=0.87$. The linear relationship in Fig. 14 supports the solid solution mechanism, and indicates the involvement of $\mathrm{H}^{+}$in the substitution. However, the stoichiometry of the solid solution is much more complicated than the nominal formula. In light of the continued difficulty of defining the structure and chemical stoichiometry of $2 \mathrm{LFh}$ (Michael et al., 2010), no further attempt has been made here to elucidate the stoichiometry of the $\mathrm{Pb}-\mathrm{Fe}$ solid solution.

\section{DISCUSSION OF PB-FE COPRECIPITATION MECHANISMS}

Laboratory studies have shown that for some systems macroscopic sorption behaviors (including $\mathrm{pH}$-dependent sorption edges and extent of uptake) differ if the contact method is CPT versus ADS (Charlet and Manceau, 1992; Crawford et al., 1993; Waychunas et al., 1993; Karthikeyan et al., 1997; Karthikeyan and Elloitt, 1999). The differences or similarities are often assumed to be caused by the atomic environment in which the trace metal is associated with the host material. Different mechanistic explanations have been offered:
(1) Separate $\mathrm{Pb}$ phases, perhaps as a result of local high $\mathrm{pH}$ during titration, were precipitated during the CPT experiments and the $\mathrm{Pb}$ phases are mechanically enveloped by iron oxyhydroxides (Schroth, 1994);

(2) CPT represents enhanced surface area or site availability (Corey, 1981; Crawford et al., 1993; Karthikeyan et al., 1997);

(3) CPT represents a greater binding strength (having multiple surface site types) over a simple precipitate surface (ADS having a single surface type) (Taylor, 1973; Crawford et al., 1993); and

(4) CPT represents solid solution formation by heavy metal incorporation into the hydrous oxide lattice (Karthikeyan et al., 1997; Martinez and Mcbride, 1998).

For the first hypothesis, our HRTEM observations have conclusively ruled out the presence of segregated high $\mathrm{Pb}$ concentration phases either inside the iron oxyhydroxide phases (occlusion) or at the edges or surfaces of these phases at the time of examination (surface precipitation). For the second and third hypothesis, geochemical modeling showed that increase of the strength of the binding constant and surface areas fit CPT sorption edge data well for the two relatively low $\mathrm{Pb}$ :Fe ratio batches (Fig. 13).

At high $\mathrm{Pb}: \mathrm{Fe}$ ratio and after about two weeks aging, our companion EXAFS study of $\mathrm{Pb}-\mathrm{Fe}$ coprecipitates collected from Batch $\mathrm{E}$ at $\mathrm{pH} 5.25$ showed that $\mathrm{Pb}$ formed a solid solution in the $\mathrm{Pb}-\mathrm{Fe}$ coprecipitate (Kelly et al., 2008). The conclusion was based on the co-refinement of the $\mathrm{Pb} \mathrm{L} \mathrm{LII-edge}$ and the Fe K-edge EXAFS spectra with the same local atomic environment. The larger atomic size of $\mathrm{Pb}$ as compared to $\mathrm{Fe}$ was accounted for in the model of the $\mathrm{FeO}_{6}$ sheet structure by displacing the $\mathrm{PbO}_{6}$ unit perpendicular to the sheet by $0.30 \pm 0.02 \AA$ from the $\mathrm{FeO}_{6}$ unit position.

A dynamic coprecipitation process may explain various lines of experimental data. HRTEM observations show that $\mathrm{Fe}^{3+}$ first precipitated out as nano-particles of 2 $3 \mathrm{~nm}$ in diameter at $\mathrm{pH}$ around $3-4$. At one $\mathrm{pH}$ unit higher $(\sim 4), \mathrm{Pb}^{2+}$ started to be adsorbed onto these nano-particles. The initial adsorption explains the $\mathrm{pH}$ spread between $\mathrm{Fe}^{3+}$ (Fig. 4) and $\mathrm{Pb}^{2+}$ (Figs. 1 and 2) removal from the aqueous solution, and the observed sorption $\mathrm{pH}$ around 4 for both CPT and ADS experiments. Access to smaller incipient particles with larger specific surface areas during the CPT experiments provides an explanation for the more efficient removal of $\mathrm{Pb}^{2+}$ in CPT than the ADS contact method.

The $\sim 2 \mathrm{~nm} 2 \mathrm{LFh}$ particles are not stable, and the coalescence to more stable $\sim 6 \mathrm{~nm}$ particles is completed within minutes (Shaw et al., 2004). Lepidocrocite of size $200 \mathrm{~nm}$ was also formed. The sample examined with EXFAS by Kelly et al. (2008) showed 40\% 2LFh and 60\% nano lepidocrocite.

During the coalescence process, $\mathrm{Pb}^{2+}$ was trapped within the iron oxyhydroxide structures and, at high $\mathrm{Pb}: \mathrm{Fe}$ ratios, part of $\mathrm{Pb}^{2+}$ formed $\mathrm{Pb}-\mathrm{Fe}$ solid solutions. A $2 \mathrm{~nm} 2 \mathrm{LFh}$ particle has only $\sim 32$ unit cells, and about $58 \%$ of $\mathrm{Fe}$ are on the surface (see Appendix A). Structure relaxation due to surface effects is great. Desorption of 
Table A1

Calculations of fraction of $\mathrm{Fe}$ atoms on the surface in a ferrihydrite structure.

\begin{tabular}{lclccc}
\hline Domain size $(\mathrm{nm})$ & Unit cells & Dimension $(\mathrm{nm})$ & Total Fe atoms & Fe at surface & Fraction on the surface \\
\hline 2 & 32 & $2.4 \times 2.4 \times 1.8$ & 320 & 184 & 0.58 \\
6 & 700 & $6 \times 6 \times 6.3$ & 7000 & 1414 & 0.20 \\
\hline
\end{tabular}

$\mathrm{Pb}-\mathrm{Fe}$ coprecipitates with EDTA show $\mathrm{Pb}^{2+}$ was not only bounded in the outer layers of $2 \mathrm{LFh}$.

Commonly, ferrihydrite is the first phase to be precipitated from an aqueous $\mathrm{Fe}^{3+}$ solution. Ferrihydrite is metastable, and over time, ferrihydrite is transformed to more stable phases (e.g., goethite and hematite) (Cornell and Schwertmann, 1996). The $\mathrm{Pb}-\mathrm{Fe}$ coprecipitates were transformed to goethite and hematite in the simulated aging experiments. Compared with control experiments on $\mathrm{Pb}$ free $2 \mathrm{LFh}$, the transformation was retarded. Desorption experiments show that the $\mathrm{Pb}^{2+}$ incorporated into goethite and hematite from the coprecipitation experiments are more stable than goethite and hematite transformed from adsorption experiments because some $\mathrm{Pb}^{2+}$ in the former case reside in the interior of the iron oxides. Therefore, our data suggest that CPT contact methods result in more permanent removal of $\mathrm{Pb}^{2+}$ by iron oxyhydroxides in the environment than that of ADS contact methods.

\section{CONCLUDING REMARKS}

Our sorption experiments have demonstrated little ambiguity that coprecipitation and adsorption contact methods have produced different behaviors of $\mathrm{Pb}^{2+}$ uptake by nano-particles of iron oxyhydroxides. Whether or not CPT and ADS can represent a more permanent sequestration of toxic metals from the environment is an important question. The answers to this and similar questions for other metals have consequences for remediation strategies and for predictions of the migration behavior of metals that coprecipitate with oxyhydroxide minerals in a wide range of settings.

However, substantial amounts of microscopic and spectroscopic work are necessary to further differentiate the uptake mechanisms, e.g., surface complexation or solid solution formation. These work are tedious and resource intensive. Only through systematic examination of this metastable and dynamic system, we can fully understand the mechanisms.

\section{ACKNOWLEDGMENTS}

The manuscript has greatly benefited from the thorough and constructive reviews of three anonymous referees and the Associate Editor Dr. Jacques Schott. This research was accomplished over a long period of time, and we owe gratitude to many individuals for assistance. We thank Greg M. Anderson and David Dzombak for encouragement and discussion at the early stages of the work. The authors would like to thank Arndt Schimmelmann for developing experimental protocol and guiding the early stage of the experimental work, and Kimberly Briggs for her assistance in conducting part of the titration experiments.

\section{APPENDIX A. SIMPLE CALCULATIONS FOR FE ATOMS IN FERRIHYDRITE STRUCTURE}

Michel et al. (2007a) presented a model for ferrihydrite with the hexagonal space group $\mathrm{Pb}_{3} m c$ and a unit cell with average dimensions of $a=\sim 5.95 \AA$ and $c=\sim 9.06 \AA$. The chemical formula is $\mathrm{Fe}_{10} \mathrm{O}_{14}(\mathrm{OH})_{2}$. Ostergren et al. (2000) suggested six possible bonding geometries for adsorption onto goethite. Ponthieu et al. (2006) indicated that a consistent description of proton and metal ion binding is possible for goethite and HFO. We used the CrystalMaker ${ }^{\mathrm{TM}}$ to construct the 2 -nm $(4 \times 4 \times 2$ unit cells $)$ and $6-\mathrm{nm}$ domains $(10 \times 10 \times 7$ unit cells), assuming ferrihydrite particles are perfect periodic stacking of unit cells and ignoring disorder and defects (e.g., stacking faults) of the structure. The numbers of $\mathrm{Fe}$ atoms are directly counted visually. We calculated the fractions of $\mathrm{Fe}$ atoms at the surface versus total $\mathrm{Fe}$ atoms in a 2 and 6-nm ferrihydrite particles (Table A1). A 2-nm ferrihydrite particle has $58 \%$ of $\mathrm{Fe}$ atoms on the surface while a $6-\mathrm{nm}$ particle has $20 \%$.

\section{REFERENCES}

Ainsworth C. C., Pilon J. L., Gassman P. L. and Van Der Sluys W. G. (1994) Cobalt, cadmium, and lead sorption to hydrous iron oxides: residence time effect. Soil Sci. Soc. Am. 58, 16151623.

Balistrieri L. S. and Murray J. W. (1982) The adsorption of Cu, Pb, $\mathrm{Zn}$, and $\mathrm{Cd}$ on goethite from major ion seawater. Geochim. Cosmochim. Acta 46, 1253-1265.

Ball J. W. and Nordstrom D. K. (1991) User's manual for WATEQ4F, with revised thermodynamic data base and test cases for calculating speciation of major, trace, and redox elements in natural waters. U.S. Geological Survey Open File Report. pp. 91-183.

Banfield J. F., Welch S. A., Zhang H., Ebert T. T. and Penn R. L. (2000) The role of aggregation in crystal growth and transformations in nanophase $\mathrm{FeOOH}$ biomineralization products. Science 289, 751-754.

Charlet L. and Manceau A. (1992) X-ray absorption spectroscopic study of the sorption of $\mathrm{Cr}(\mathrm{III})$ at the oxide water interface. 2 . Adsorption, coprecipitation, and surface precipitation on hydrous ferric-oxide. J. Colloid Interf. Sci. 148, 443-470.

Corey R. B. (1981) Adsorption vs. precipitation. In Adsorption of Inorganics at Solid-Liquid Interfaces (eds. M. A. Anderson and A. J. Rubin). Annals of Arbor Science Publisher, Ann Arbor, MI, pp. 161-182.

Cornell R. M. and Schwertmann U. (1996) The Iron Oxides: Structures, Properties, Reactions, Occurrence and Uses. VCH, Inc., New York.

Crawford R. J., Harding I. H. and Mainwaring D. E. (1993) Adsorption and coprecipitation of single heavy metal ions onto the hydrated oxides of iron and chromium. Langmuir 9, 30353056. 
Davis J. A. and Kent D. B. (1990) Surface complexation modeling in aqueous geochemistry. Mineral-Water Interface Geochem. 23, $177-260$.

Dyer J. A., Triverdi P., Scrivner N. C. and Sparks D. L. (2003) Lead sorption onto ferrihydrite. 2. Surface complexation modeling. Environ. Sci. Technol. 37, 915-922.

Dzombak D. A. and Morel F. M. M. (1990) Surface Complexation Modeling: Hydrous Ferric Oxide. John Wiley \& Sons, New York.

Farley K. J., Dzombak D. A. and Morel F. M. M. (1985) Surface precipitation model for the sorption of cations on metal oxides. J. Colloid Interf. Sci. 106, 226-242.

Ford R., Bertsch P. M. and Farley K. J. (1997) Changes in transition and heavy metal partitioning during hydrous iron oxide aging. Environ. Sci. Technol. 31, 2028-2033.

Ford R. T., Kemner K. M. and Bertsch P. M. (1999) Influence of sorbate-sorbent interactions on the crystallization kinetics of nickel- and lead-feerihydrite coprecipitates. Geochim. Cosmochim. Acta 63, 39-48.

Gadde R. R. and Laitinen H. A. (1973) Study of the sorption of lead by hydrous ferric oxide. Environ. Lett. 5, 223-235.

Ganguly J. and Saxena S. K. (1987) Mixtures and Mineral Reactions. Springer-Verlag.

Hayes K. F. and Leckie J. O. (1986) Mechanism of lead ion adsorption at the goethite-water interface. In Geochemical Processes at Mineral Surfaces (eds. J. A. Davis and K. F. Hayes). Proc. Am. Chem. Soc. Symp. Ser. 323, ACS, Washington, DC. pp. 114-141.

Jambor J. L. and Dutrizac J. E. (1998) Occurrence and constitution of natural and synthetic ferrihydrite, a widespread iron oxyhydroxide. Chem. Rev. 98, 2549-2585.

Janney D. E., Cowley J. M. and Buseck P. R. (2000) Structure of synthetic 2-line ferrihydrite by electron nanodiffraction. Am. Mineral. 85, 1180-1187.

Jenne E. A. (1968) Controls on $\mathrm{Mn}, \mathrm{Co}, \mathrm{Ni}, \mathrm{Cu}$, and $\mathrm{Zn}$ concentrations in soils and water: the significant role of hydrous $\mathrm{Mn}$ and $\mathrm{Fe}$ oxides. In Trace Inorganic in Water (ed. R. A. Baker). American Chemical Society, Washington DC.

Karthikeyan K. G., Elliott H. A. and Cannon F. S. (1997) Adsorption and coprecipitation of copper with the hydrous oxides of iron and aluminum. Environ. Sci. Technol. 31, 27212725.

Karthikeyan K. G. and Elloitt H. A. (1999) Surface complexation modeling of copper sorption by hydrous oxides of iron and aluminum. J. Colloid Interf. Sci. 220, 88-95.

Karthikeyan K. G., Elloitt H. A. and Chorover J. (1999) Role of surface precipitation in copper sorption by the hydrous oxides of iron and aluminum. J. Colloid Interf. Sci. 209, 7278.

Kelly S., Lu P., Bolin T., Chattopadhyay S., Newville M. G., Shibata T. and Zhu C. (2008) Molecular structure of $\mathrm{Pb}(\mathrm{II})$ coprecipitated with $\mathrm{Fe}(\mathrm{III})$ oxyhydroxide. In Adsorption of Metals by Geomedia II (eds. M. Barnett and D. Kent). Developments in Earth \& Environmental Sciences 7, Elsevier. pp. 67-94.

Kinniburgh D. G., Jackson M. L. and Syers J. K. (1976) Adsorption of alkaline earth, transition, and heavy metal cations by hydrous oxide gels of iron and aluminum. Soil Sci. Soc. Am. J. 40, 796-799.

Krauskopf K. B. (1956) Factors controlling the concentration of thirteen rare metals in seawater. Geochim. Cosmochim. Acta $\mathbf{9}$, $1-24$.

Lutzenkirchen J. (1997) Ionic strength effects on cation sorption to oxides: macroscopic observations and their significance in microscopic interpretation. J. Colloid Interf. Sci. 195, 149-155.
Martinez C. E. and McBride M. B. (1998) Solubility of $\mathrm{Cd}^{2+}$, $\mathrm{Cu}^{2+}, \mathrm{Pb}^{2+}$, and $\mathrm{Zn}^{2+}$ in aged coprecipitates with amorphous iron hydroxides. Environ. Sci. Technol. 31, 743-748.

Martinez C. E. and McBride M. B. (2001) Cd, Cu, Pb, and $\mathrm{Zn}$ coprecipitation in $\mathrm{Fe}$ oxide formed at different $\mathrm{pH}$ : Aging effects on metal solubility and extractability by citrate. Environ. Toxicol. Chem. 20, 122-126.

Michel F. M., Ehm L., Antao S. M., Lee P. L., Chupas P. J., Liu G., Strongin D. R., Schoonen M. A. A., Phillips B. L. and Parise J. B. (2007a) The structure of ferrihydrite, a nanocrystalline material. Science 316, 1726-1729.

Michel F. M., Ehm L., Liu G., Han W. Q., Antao S. M., Chupas P. J., Lee P. L., Knorr K., Eulert H., Kim J., Grey C. P., Celestian A. J., Gillow J., Schoonen M. A. A., Strongin D. R. and Parise J. B. (2007b) Similarities in 2- and 6-line ferrihydrite based on pair distribution function analysis of X-ray total scattering. Chem. Mater. 19, 1489-1496.

Nordstrom D. K., Plummer L. N., Langmuir D., Busenberg E., May H. M., Jones B. and Parkhurst D. L. (1990) Revised chemical equilibrium data for major water-mineral reactions and their limitations. In Chemical Modeling of Aqueous Systems II (eds. D. C. Melchior and R. L. Bassett). American Chemical Society.

Nriagu J. O. (1992) Modern history of lead poisoning: a century of discovery and rediscovery. In Human Lead Exposure (ed. H. Needleman). CRC Press, Boca Raton.

Parkhurst D. L. and Appello A. A. J. (1999) User's guide to PHREEQC (version 2) - a computer program for speciation, batch-reaction, one-dimensional transport, and inverse geochemical modeling. U.S. Geological Survey, Water-Resource Investigation Report. pp. 99-4259.

Penn R. L., Zhu C., Xu H. and Veblen D. R. (2001) Iron oxide coatings on sand grains from the Atlantic coastal plain: HRTEM characterization. Geology 29, 843-846.

Ponthieu M., Juillot F., Hiemstra T., van Riemsdijk W. H. and Benedetti M. F. (2006) Metal ion binding to iron oxides. Geochim. Cosmochim. Acta 70, 2679-2698.

Pokrovsky O. S., Pokrovski G. S., Schott J. and Galy A. (2006a) Experimental study of germanium adsorption on goethite and germanium coprecipitation with iron hydroxide: X-ray absorption fine structure and macroscopic characterization. Geochim. Cosmochim. Acta 70, 3325-3341.

Pokrovsky O. S., Schott J. and Dupre B. (2006b) Trace element fractionation and transport in boreal rivers and soil porewaters of permafrost-dominated basaltic terrain in Central Siberia. Geochim. Cosmochim. Acta 70, 3239-3260.

Rose A. W. and Bianchimosquera G. C. (1993) Adsorption of $\mathrm{Cu}$, $\mathrm{Pb}, \mathrm{Zn}, \mathrm{Co}, \mathrm{Ni}$, and $\mathrm{Ag}$ on goethite and hematite; a control on metal mobilization from red beds into stratiform copper deposits. Econ. Geol. Bull. Soc. Econ. Geol. 88, 1226-1236.

Schroth J. (1994) Unipure technology removes heavy-metals from waste-water. Hazard. Waste Consult. 12, A33-34.

Schultz M. F., Benjamin M. M. and Ferguson J. F. (1987) Adsorption and desorption of metals on ferrihydrite: reversibility of the reaction and sorption properties of the regenerated solid. Environ. Sci. Technol. 21, 863-869.

Schwertmann U. and Cornell R. M. (1991) Iron oxides in the laboratory: preparation and characterization. $\mathrm{VCH}$, New York.

Schwertmann U. and Fitzpatrick R. W. (1977) Occurrence of lepidocrocite and its association with goethite in Natal soils. Soil Sci. Soc. Am. J. 41, 1013-1018.

Schwertmann U. and Taylor R. M. (1972a) The influence of silicate on the transformation of lepidocrocite to goethite. Clay Clay Mineral. 20, 159-164.

Schwertmann U. and Taylor R. M. (1972b) Transformation of lepidocrocite to goethite. Clay Clay Mineral. 20, 151-158. 
Shaw S., Benning L. G., Terrill N. J. and Davidson L. (2004) Nucleation and growth of iron oxyhydroxide nanoparticles from solution: An in situ time-resolved small angle X-ray scattering (SAXS) study. Geochem. Cosmochim. Acta 68, A158.

Sposito G. (1984) The Surface Chemistry of Soils. Oxford University Press, New York.

Sverjensky D. A. (2003) Standard states for the activities of mineral surface sites and species. Geochim. Cosmochim. Acta 67, 17-28.

Swallow K. C., Hume D. N. and Morel M. M. (1980) Sorption of copper and lead by hydrous ferric oxides. Environ. Sci. Technol. 14, 1326-1331.

Taylor H. F. W. (1973) Crystal structure of some double hydroxide minerals. Mineral. Mag. 39, 377-389.

Trivedi P., Dyer J. and Sparks D. (2003) Lead sorption onto ferrihydrite. 1. A macrscopic and spectroscopic assessment. Environ. Sci. Technol. 37, 908-914.

Venema P., Hiemstra T. and Van Riemsdijk W. H. (1996) Comparison of different site binding models for cation sorption: description of $\mathrm{pH}$ dependency, salt dependency, and cationproton exchange. J. Colloid Interf. Sci. 181, 45-59.
Wagman D. D., Evans W. H., Parker V. B., Schumm R. H., Halow I., Bailey S. M., Churney K. L. and Nuttall R. L. (1982) The NBS tables of chemical thermodynamic properties: selected values for inorganic and $\mathrm{Cl}$ and $\mathrm{C} 2$ substances in SI units. $J$. Phys. Chem. Reference Data 11, Suppl. No. 2.

Walton A. G. (1967) The Formation and Properties of Precipitates. Wiley, New York, 44p.

Waychunas G. A., Fuller C. C. and Davis J. A. (2002) Surface complexation and precipitation geometry for aqueous $\mathrm{Zn}$ (II) sorption on ferrihydrite I: X-ray absorption extended fine structure spectroscopy analysis. Geochim. Cosmochim. Acta 66, $1119-1137$.

Waychunas G. A., Rea B. A., Fuller C. C. and Davis J. A. (1993) Surface chemistry of ferrihydrite: I. EXAFS studies of the geometry of coprecipitated and adsorbed arsenate. Geochim. Cosmochim. Acta 57, 2251-2269.

Westall J. C. and Hohl H. (1980) A comparison of electrostatic models for the oxide/solution interface. Adv. Colloid Interface Sci. 12, 265-294.

Associate editor: Jacques Schott 